\title{
Avaliação de requisitos de desempenho de Sistemas de Proteção Periférica (SPP)
}

\author{
Evaluation of performance requirements for Temporary \\ Edge Protection Systems (TEPS)
}

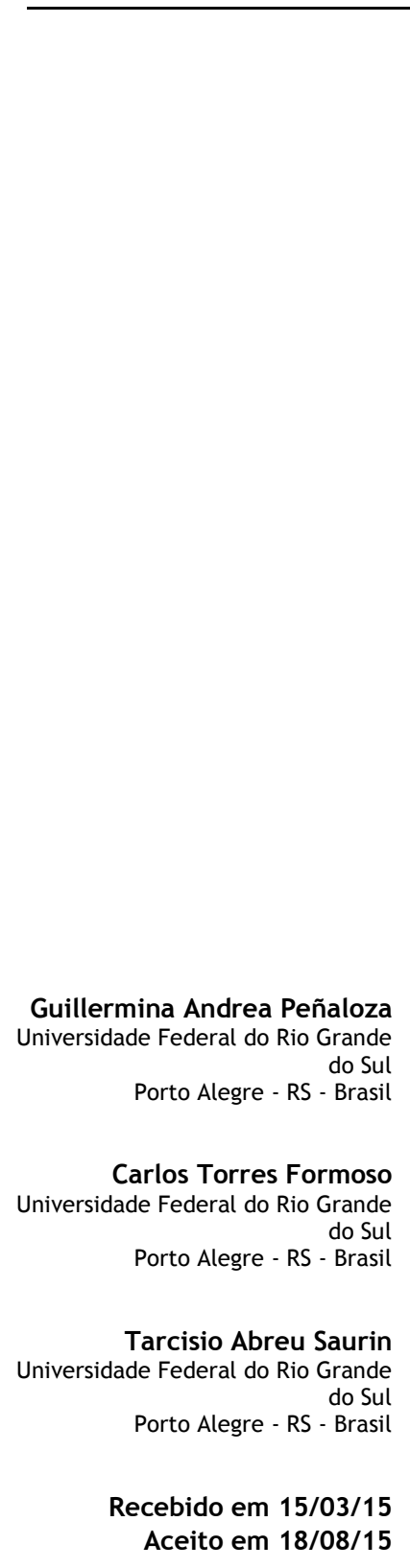

\section{Guillermina Andrea Peñaloza \\ Carlos Torres Formoso \\ Tarcisio Abreu Saurin}

\section{Resumo}

$\mathbf{E}$

mbora o uso de sistemas de proteções periféricas (SPP) seja importante para prevenir quedas de altura na construção civil, a literatura não apresenta de forma abrangente os requisitos de desempenho para a avaliação do desempenho dos mesmos. O objetivo deste estudo consiste em propor um conjunto de requisitos para avaliar o desempenho para estes sistemas. Foi desenvolvido um protocolo que contém critérios qualitativos e quantitativos para a avaliação de desempenho em relação a 33 requisitos de desempenho, sendo 15 referentes à segurança, 12 à eficiência e 6 à flexibilidade. Para ilustrar a aplicação deste protocolo, foi avaliado um conjunto de equipamentos disponíveis no mercado da Região Metropolitana de Porto Alegre RS, de madeira, metálicos e mistos. Os resultados das avaliações desses equipamentos foram discutidos com representantes de empresas construtoras, especialistas em segurança no trabalho, projetistas e fornecedores de SPP, com a finalidade de propor melhorias nestes equipamentos. Os pontos fortes e fracos de cada sistema são discutidos com base nessas aplicações.

Palavras-chave: Sistemas de proteção periférica. Requisitos de desempenho. Segurança e saúde no trabalho.

\begin{abstract}
Although the use of temporary edge protection systems (TEPS) is an important measure to prevent falls from heights on construction sites, the literature does not present a comprehensive set of performance requirements for those systems. The aim of this study is to propose a set of requirements for assessing the performance of TEPS. A protocol was developed, containing qualitative and quantitative criteria for assessing the performance in relation to 33 performance requirements, in which 15 are related to safety, 12 to efficiency and 6 to flexibility. The application of this protocol is illustrated in the evaluation of a number of equipment available in the Metropolitan Region of Porto Alegre, made of wood, steel, and mixed materials. The results of the evaluation were discussed with representatives of construction companies, safety experts, designers of TEPS, and suppliers of those systems. The limitations and strengths of each TEPS are discussed based on those applications.
\end{abstract}

Keywords: Temporary edge protection systems. Performance requirements. Safety and health at work. 


\section{Introdução}

Uma das proteções físicas mais comumente utilizadas nos canteiros de obra são os sistemas de proteção periférica (SPP), os quais oferecem proteção passiva e simultânea a vários trabalhadores, impedindo a queda de altura (GARCIA, 2010). No Brasil, de acordo com um informe sobre embargos e interdições realizado pelo Ministério de Trabalho e Emprego (BRASIL, 2013), os SPP encontram-se entre os dez equipamentos que mais frequentemente causam interdições de canteiros de obras. De fato, há evidências de que os requisitos associados aos SPP costumam ser os menos atendidos entre aqueles da NR 18 (SAURIN; LANTELME; FORMOSO, 2000; MALLMANN, 2008; CAMBRAIA; FORMOSO, 2011; COSTELLA; JUNGES; PILZ, 2014). Deficiências comumente encontradas estão relacionadas à fragilidade dos componentes que integram os SPP, à ausência de projeto e memorial de cálculo, à ausência ou insuficiente especificação do equipamento de proteção individual (EPI), a ser utilizados para a instalação, manutenção e remoção do SPP (BRASIL, 2013). Entre as possíveis causas dessa situação pode ser citada a falta de soluções de SPP adequadas às características tecnológicas e gerenciais das obras. Por outro lado, estudos no Brasil e no exterior (OSTROW, 2001; MARTINS, 2004; LAN; DAIGLE, 2009, GARCIA, 2010; CHEUNG, 2012) identificaram boas soluções de SPP. Apesar disso, é reconhecida a crescente expansão do número de fornecedores de equipamentos de proteção coletiva tanto no mercado brasileiro como em outros países (SCANMETAL, 2011; METRO..., 2009; ORMAN, 2012). Contudo, a quantidade de requisitos disseminados em diversas normas e a falta de métodos para verificar a aderência dos SPP aos requisitos das normas e outros requisitos relevantes criam dificuldades para todas as partes interessadas, tais como órgãos governamentais de fiscalização, os próprios operários encarregados pela execução dos SPP e empresas construtoras, as quais carecem de ferramentas para comparar a eficiência e eficácia dos diferentes sistemas disponíveis no mercado. O objetivo deste trabalho é propor um conjunto de requisitos de desempenho para SPP. Foram definidos critérios qualitativos e quantitativos, utilizados para a construção de um protocolo de avaliação de desempenho desses sistemas. São apresentados exemplos de aplicação desse protocolo em três tipos de SPP, de madeira, misto e metálico. A avaliação de um conjunto de equipamentos disponíveis no mercado da Região Metropolitana de Porto Alegre, RS, ilustra como esse protocolo pode contribuir para a análise de soluções existentes no mercado, que podem ser objeto de aperfeiçoamento.

\section{Sistemas de Proteção Periférica (SPP)}

As normas brasileiras, bem como as de outros países, definem trabalho em altura a toda atividade executada acima de $2,0 \mathrm{~m}$ do nível inferior onde haja risco de queda (BRASIL, 2014a; ASOCIACIÓN..., 2004; OCCUPATIONAL..., 1996; CANADIAN..., 1981). Entre as causas dos riscos de quedas em altura, algumas comumente apontadas são a falta de treinamento dos trabalhadores, procedimentos de trabalho difíceis de ser cumpridos, restrições do leiaute e falta de barreiras de proteção contra quedas (HSIAO; SIMEONOV, 2001; JOHNSON; SINGH; YOUNG, 1998; BROWN; FRANK, 1997). Tendo em vista a prevenção de quedas, em primeiro lugar devem-se adotar estratégias preventivas que eliminem os riscos de queda na origem. Nesse sentido, o conceito de prevenção através do projeto - prevention through design - (GAMBATESE; BEHM; HINZE, 2005; TOOLE; CARPENTER, 2012) é bastante útil, na medida em que é enfatizada a aplicação de medidas de proteção integradas aos projetos da edificação, especialmente 0 arquitetônico. Caso não seja possível eliminar os riscos, devem ser adotadas estratégias com o objetivo de proteger as pessoas das consequências da queda em altura, tais como o uso de EPI, redes ou dispositivos similares. Entre as proteções contra quedas dispostas na NR 18 (BRASIL, 2014b), este trabalho enfatiza os SPP do tipo guarda-corpo e rodapé (GcR), por serem os mais comumente utilizados nos canteiros de obra de edificações verticais e objeto frequente de embargos e interdições. Os SPP têm como principal vantagem sua natureza passiva, o que significa que os trabalhadores não precisam realizar nenhuma ação para que o sistema tenha o efeito desejado, ao contrário do que ocorre com os EPI. A escolha de proteções físicas contra quedas em altura, entre as quais os SPP são uma das opções, envolve uma série de critérios que devem levar em conta os riscos existentes e particularidades das atividades desempenhadas em um canteiro de obra. Cameron, Gillan e Duff (2007) afirmam que o critério mais importante deve ser sempre a segurança dos trabalhadores e do público em geral, sendo critérios secundários o impacto no prazo e custo da obra. Por isso, é importante conhecer o desempenho dos SPP para

268 Peñaloza, G. A.; Formoso, C. T.; Saurin, T. A. 
propor recomendações sobre como devem ser interpretados e utilizados em diferentes contextos.

As normas de segurança e saúde no trabalho (SST) na construção civil, no Brasil e no exterior, apresentam vários requisitos aos quais os SPP devem atender. De acordo com a ABNT (2013), os requisitos são condições que expressam qualitativamente as propriedades que um produto deve possuir a fim de satisfazer as exigências dos usuários. Para determinar o desempenho de um produto as exigências do usuário são traduzidas em requisitos e critérios. Ainda segundo a ABNT (2013), os critérios são especificações quantitativas ou qualitativas dos requisitos, expressos em termos mensuráveis, a fim de que possam ser objetivamente determinados. Contudo, a maioria das normas consultadas neste trabalho, NR 18 (BRASIL, 2014a), RTP 01 (FUNDACENTRO, 2003), OSHA 1926.502 (OCCUPATIONAL..., 1996), UNE-EN (ASOCIACIÓN..., 2004), S-2.1 (CANADIAN..., 1981), apresenta requisitos de resistência estrutural e configuração geométrica dos SPP, negligenciando a eficiência e a flexibilidade deles, bem como não tratam dos processos de montagem e desmontagem. No Brasil, o item 18.13 da NR 18 estabelece que o SPP destina-se a promover proteção contra riscos de queda de pessoas, materiais e ferramentas (BRASIL, 2014b). Visando ilustrar como as exigências da NR 18 podem ser atendidas, a Fundacentro (2003) publicou a Recomendação Técnica de Procedimentos - RTP 01 "Medidas de Proteção contra Quedas de Altura”. A RTP 01 apresenta exigências adicionais em relação à NR 18 , notadamente a de que os componentes do SPP tenham resistência a esforços de $150 \mathrm{kgf} / \mathrm{metro}$ linear. Por outro lado, no Brasil os órgãos regulamentadores e de físcalização costumam considerar os requisitos de normas estrangeiras para aperfeiçoar as normas nacionais e lidar com lacunas. Entre essas merece destaque a norma europeia UNE-EN 13374 (ASOCIACIÓN..., 2004), por apresentar requisitos detalhados para ensaios estruturais dos SPP, tema ainda não contemplado nas normas nacionais.

\section{Método de pesquisa Delineamento da pesquisa}

Esta pesquisa foi dividida em quatro etapas:

(a) identificação de requisitos;

(b) categorização dos requisitos; (c) definição de um sistema de avaliação e estabelecimento das fontes de evidências para avaliar cada requisito; e

(d) aplicação e avaliação do protocolo.

A primeira etapa foi desenvolvida por meio da identificação de requisitos provenientes de normas nacionais e internacionais. Por outro lado, a definição de novos requisitos e das fontes de evidências surgiu a partir de entrevistas e grupos de discussão com engenheiros responsáveis por obras que usavam SPP, engenheiros e técnicos em segurança e saúde no trabalho, projetistas de proteções coletivas, auditores fiscais, representantes de empresas que fornecem SPP e trabalhadores responsáveis pela execução dos SPP. Nesta etapa o protocolo foi testado em sete obras, e os resultados dessas aplicações foram apresentados e discutidos em reuniões com representantes e projetistas das empresas construtoras envolvidas.

$\mathrm{Na}$ segunda etapa houve a classificação dos requisitos de acordo com a natureza de cada um, em três categorias:

(a) segurança;

(b) eficiência; e

(c) flexibilidade.

Aqui também foi realizado um workshop, que envolveu a participação conjunta de representantes de várias partes com a finalidade de discutir os resultados de novas aplicações do protocolo e identificar oportunidades de melhorias nos SPP avaliados.

$\mathrm{Na}$ terceira etapa da pesquisa o protocolo foi dividido em duas partes: a primeira com ênfase na avaliação dos requisitos na situação de projeto; e a segunda na situação de uso dentro do canteiro de obras. Para cada requisito foram estabelecidos critérios de avaliação.

$\mathrm{Na}$ quarta e última etapa, foram realizadas aplicações do protocolo por outros pesquisadores, que não são autores deste artigo, como forma de avaliar a facilidade de uso dele. Dessa forma, a partir da retroalimentação desses outros pesquisadores, bem como da experiência acumulada ao longo de todas as etapas, foi consolidado o protocolo de avaliação de requisitos de desempenho de SPP.

\section{Identificação de requisitos}

Os requisitos de SPP foram identificados a partir de pesquisa bibliográfica/análise documental e entrevistas. No que diz respeito à primeira fonte, foram consultadas normas e regulamentos 
nacionais como NR 18 (BRASIL, 2014b) e RTP 01 (FUNDACENTRO, 2003), normas internacionais tais como a UNE-EN 13374 (ASOCIACIÓN..., 2004), OSHA 1926.502 (OCUPATIONAL..., 1996) e S-2.1 (CANADIAN..., 1981), artigos científicos (LAN; DAIGLE, 2009; CHEUNG, 2012; SULOWSKI, 2014), três memoriais descritivos de SPP patenteados (MCLAUGHLIN; MCCOY, 1976; HOLLOMAN, 1994; OSTROW, 2001) e análise de relatórios técnicos de ensaios laboratoriais encomendada pelo Sindicato da Indústria da Construção (Sinduscon/RS) para verificação dos requisitos de carga estática de três tipos de SPP (madeira, misto e metálico) realizada pelo Instituto Tecnológico em Desempenho e Construção Civil da Universidade do Vale do Rio dos Sinos (Unisinos).

A segunda fonte de identificação de requisitos foram entrevistas individuais e discussões em seminários e workshops com um grupo de trabalho. Tal grupo era integrado por representantes de sete empresas construtoras, as quais tinham interesse numa avaliação independente dos SPP, bem como auditores fiscais do trabalho, projetistas e fornecedores de SPP. A Tabela 1 apresenta o perfil dos participantes entrevistados. As entrevistas individuais foram gravadas e transcritas, tiveram duração média de $1 \mathrm{~h}$ e foram baseadas num roteiro de quinze questões, que dava origem a outras no decorrer da entrevista. As entrevistas abordavam os requisitos de normas, problemáticas e oportunidades de melhoria dos SPP. A partir das transcrições de entrevistas, discussões e documentos consultados, foram identificados 33 requisitos de SPP.

\section{Categorização dos requisitos}

Os 33 requisitos identificados foram agrupados nas três categorias já mencionadas:

(a) 15 requisitos de segurança;

(b) 12 requisitos de eficiência; e

(c) 6 requisitos de flexibilidade.

Os requisitos da categoria segurança têm origem em sua maioria (87\%) nas normas e estão associados a resistência estrutural, durabilidade e dimensões. Assim como ocorre nas outras duas categorias, os requisitos associados à segurança são relacionados entre si. Por exemplo, o atendimento do requisito "minimizar riscos de queda de pessoas" depende de outros dois requisitos: um relacionado à resistência do SPP aos esforços solicitantes e outro referente à adequada fixação à estrutura de sustentação.
Desse modo, o atendimento a determinados requisitos contribui para o atendimento de outros. Já a maioria $(83 \%)$ dos requisitos da categoria eficiência dos SPP teve origem em entrevistas, observações durante o uso dos SPP e análise de projetos, indicando que as normas negligenciam esse tipo de requisito. Os requisitos ligados à eficiência contemplam requisitos ergonômicos, de produtividade, reaproveitamento e custo ao longo do ciclo de vida. No que se refere à flexibilidade, esta pode ser definida como a capacidade de um produto ou serviço responder às mudanças nas condições dentro de um tempo curto, com baixos recursos e sem perdas no desempenho (THOMKE, 1997; UPTON, 1995). Dessa maneira, o SPP deve ser adaptável à mudança em relação a configurações geométricas, detalhes, distintas etapas de obra e diferentes técnicas construtivas. Similarmente à categoria eficiência, os requisitos associados à flexibilidade também tiveram origem em sua maioria (83\%) nas entrevistas e análise de SPP encontrados no mercado.

\section{Níveis de atendimento}

Para cada requisito $(R)$ foram estabelecidos critérios de avaliação $(C)$. Ao todo foram propostos 40 critérios entre os requisitos de análise de projeto e análise em uso dos SPP. Contudo, no presente estudo alguns critérios possuem caráter qualitativo, visto que alguns requisitos não puderam ser quantificados por sua natureza. Além disso foi proposto um sistema de avaliação em quatro níveis, atende (1 ponto); atende parcialmente ( 0,5 ponto); não atende ( 0 ponto); e não se aplica. Devido à limitação de tempo deste estudo, a caracterização da amostra estabelece que a avaliação em uso de cada requisito deve ser realizada em dois pavimentostipo de cada obra visitada. Em cada pavimento devem ser escolhidos quatro trechos diferentes de SPP na periferia da edificação. Em cada trecho, devem ser escolhidos três módulos adjacentes de SPP para ser avaliados (Figura 1). Por sua vez, no momento da escolha devem ser consideradas situações na quais há claramente uma falha entre os módulos de cada trecho, como instabilidade ou deslocamento dos montantes verticais, incorreta fixação à estrutura de sustentação, frestas entre o rodapé e a superfície de trabalho, e componentes deteriorados. A nota do requisito é dada pela média de atendimento entre os dois pavimentos. Por exemplo, o SPP em madeira obteve $63 \%$ de atendimento ao requisito "minimizar riscos de queda de materiais e ferramentas". Isso significa que $63 \%$ dos requisitos de todos os trechos avaliados foram atendidos, em média. 


\section{Fontes de evidências}

A fim de facilitar a aplicação do protocolo foram definidas as fontes de evidências para avaliar cada requisito. Por exemplo, requisitos vinculados ao projeto do SPP exigem a análise de especificações, dimensões, materiais e procedimentos de execução, entre outros. Similarmente, a avaliação da resistência dos SPP aos esforços solicitantes necessariamente requer a consulta aos laudos técnicos de ensaio laboratorial. Já outros requisitos exigem a análise em uso, principalmente aqueles associados às tarefas de montagem e desmontagem do SPP. Ainda, outros requisitos exigem a realização de entrevistas com a gerência da obra, trabalhadores e projetistas, como no caso dos requisitos " $O S P P$ tem baixo custo ao longo do ciclo de vida" e "os componentes do SPP podem ser reaproveitados em obras futuras". O Quadro 1 apresenta um exemplo de como os requisitos foram organizados e parametrizados, bem como a forma de apresentação das fontes de evidências. Visando a permitir a rastreabilidade dos requisitos e critérios foi listada também a fonte que deu origem a eles.

\section{Escolha dos SPP e caracterização das obras visitadas}

Foram escolhidos nove tipos de SPP para a aplicação do protocolo. A escolha deles ocorreu em função de empresas construtoras locais terem desenvolvido recentemente projetos de SPP de madeira, metálicos e mistos, e terem interesse em uma avaliação independente deles. O Quadro 2 apresenta as características de cada sistema avaliado.

Tabela 1 - Perfil dos participantes entrevistados

\begin{tabular}{c|l|l|c}
\hline Qtd. & \multicolumn{1}{|c|}{ Atividade profissional } & \multicolumn{1}{c}{ Empresa/Instituição } & Tempo de experiência \\
\hline 12 & Engenheiros civis & Empresas construtoras & entre 4 e 13 anos \\
\hline 06 & Engenheiros em SST & Empresas construtoras & entre 1 e 6 anos \\
\hline 10 & Técnicos em SST & Empresas construtoras & entre 6 meses e 2 anos \\
\hline 03 & Projetistas de SPP & Empresas de consultoria em SST & 6,11 e 30 anos \\
\hline 03 & Auditores Fiscais do Trabalho & Ministério do Trabalho e Emprego & 18,20 e 25 anos \\
\hline 02 & $\begin{array}{l}\text { Fornecedores de SPP } \\
\text { industrializados }\end{array}$ & $\begin{array}{l}\text { Empresas nacionais e regionais } \\
\text { fornecedoras de SPP }\end{array}$ & 13 e 18 anos \\
\hline 18 & Trabalhadores que executam SPP & Empresas terceirizadas em SST & entre 5 meses e 7 anos \\
\hline
\end{tabular}

Figura 1 - Escolha dos trechos de SPP a serem avaliados

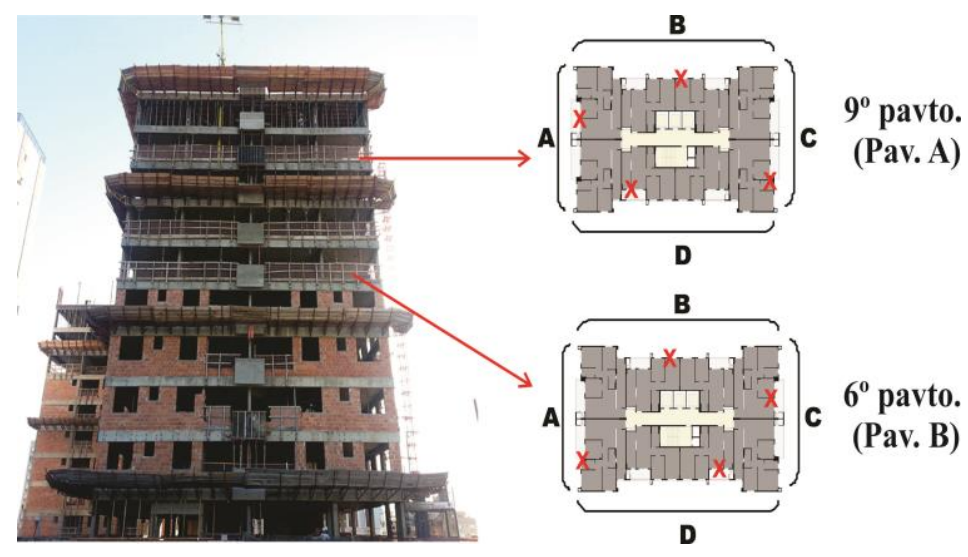


Quadro 1 - Extrato do instrumento de coleta de dados

\begin{tabular}{|c|c|c|}
\hline \multicolumn{3}{|l|}{ Etapa 1 - Análise do Proj } \\
\hline \multicolumn{3}{|c|}{$\begin{array}{l}\text { Antes da visita à obra, solicitar à empresa construtora o projeto do SPP. Avaliar os requisitos de projeto a } \\
\text { fim de se familiarizar com o mesmo e antecipar características críticas a levar em conta na próxima etapa } \\
\text { (análise em uso). }\end{array}$} \\
\hline \multicolumn{3}{|l|}{ Requisitos } \\
\hline \multicolumn{3}{|c|}{ Categoria: Segurança } \\
\hline \multicolumn{3}{|c|}{$\boldsymbol{R}:$ O projeto especifica a resistência às cargas estáticas previstas pela norma (BRASIL, 2014b) } \\
\hline \multicolumn{2}{|c|}{$\begin{array}{l}C: \text { Carga pontual de } 150 \mathrm{kgF} / \mathrm{m} \text {. no travessão superior e montante, } 70 \mathrm{KgF} / \mathrm{m} \text {. no } \\
\text { travessão intermediário e rodapé (BRASIL, 2014b). }\end{array}$} & SIM/NÃO/AP/NA \\
\hline \multicolumn{3}{|c|}{ Categoria: Eficiência } \\
\hline \multicolumn{3}{|c|}{ R: O projeto prevê que o SPP seja reaproveitado em obras futuras, estimando sua vida útil (Entrevista) } \\
\hline \multicolumn{2}{|c|}{$\begin{array}{l}C: \text { Especificação do período em que o SPP se presta às atividades para as quais } \\
\text { foram projetados (BRASIL, 2013). }\end{array}$} & SIM/NÃO/AP/NA \\
\hline \multicolumn{3}{|c|}{ Categoria: Flexibilidade } \\
\hline \multicolumn{3}{|c|}{$\boldsymbol{R}:$ O projeto especifica componentes fáceis de manipular e transportar (Entrevista) } \\
\hline \multicolumn{2}{|c|}{$\begin{array}{l}C: \text { Os componentes devem ter dimensões que não comprometam a segurança e } \\
\text { saúde do trabalhador (BRASIL, 2014c). }\end{array}$} & SIM/NÃO/AP/NA \\
\hline \multicolumn{3}{|c|}{ Etapa $2-$ Análise em Uso do SPP } \\
\hline \multicolumn{3}{|c|}{$\begin{array}{l}\text { A análise em uso compreende: avaliação do SPP já instalado no local bem como a avaliação da } \\
\text { montagem e desmontagem do SPP. A mesma deverá ser acompanhada de registro fotográfico. Os } \\
\text { requisitos dimensionais deverão ser verificados com trena métrica. Para avaliar os requisitos sobre } \\
\text { esforço físico ver Anexo } 1 \text {. }\end{array}$} \\
\hline Requisitos & Pav. A & Pav. B \\
\hline \multicolumn{3}{|c|}{ Categoria: Segurança } \\
\hline \multicolumn{3}{|c|}{$\begin{array}{l}\boldsymbol{R}: \text { O SPP está fixado à estrutura de acordo com as indicações do projetista ou fabricante (BRASIL, } \\
\text { 2014b). }\end{array}$} \\
\hline \multirow{4}{*}{$\begin{array}{l}C: \text { Os mecanismos para fixar o SPP à estrutura estão de } \\
\text { acordo com os especificados no projeto (Entrevista) }\end{array}$} & SIM/NÃO/AP/NA & SIM/NÃO/AP/NA \\
\hline & SIM/NÃO/AP/NA & SIM/NÃO/AP/NA \\
\hline & SIM/NÃO/AP/NA & SIM/NÃO/AP/NA \\
\hline & SIM/NÃO/AP/NA & SIM/NÃO/AP/NA \\
\hline \multicolumn{3}{|c|}{ Categoria: Eficiência } \\
\hline \multicolumn{3}{|c|}{$\boldsymbol{R}:$ Não há interferências do SPP com outros equipamentos (Entrevista) } \\
\hline \multirow{4}{*}{$\begin{array}{l}C: \text { Conflitos com equipamentos tais como: plataformas de } \\
\text { proteção, andaimes, escoras, entre outros (Entrevista) }\end{array}$} & SIM/NÃO/AP/NA & SIM/NÃO/AP/NA \\
\hline & SIM/NÃO/AP/NA & SIM/NÃO/AP/NA \\
\hline & SIM/NÃO/AP/NA & SIM/NÃO/AP/NA \\
\hline & SIM/NÃO/AP/NA & SIM/NÃO/AP/NA \\
\hline \multicolumn{3}{|c|}{ Categoria: Flexibilidade } \\
\hline \multicolumn{3}{|c|}{$\boldsymbol{R}:$ O projeto prevê o uso do mesmo SPP em todas as etapas da obra (Entrevista) } \\
\hline \multicolumn{2}{|c|}{$\begin{array}{l}C: \text { Adapta-se a todas as etapas da obra nas quais existem riscos de queda, tais } \\
\text { como: forma, estrutura e vedação (Entrevista). }\end{array}$} & SIM/NÃO/AP/NA \\
\hline
\end{tabular}




\section{Quadro 2 - Características dos SPP avaliados}

\begin{tabular}{|c|c|}
\hline \multicolumn{2}{|l|}{$\begin{array}{ll}\text { MADEIRA (MA-1) } \\
\end{array}$} \\
\hline $\begin{array}{l}\text { Sistema em madeira com tela de proteção. A união dos componentes ocorre mediante } \\
\text { pregos. Os montantes são fixados na viga mediante barra de ancoragem, arruela e } \\
\text { porca do tipo borboleta. Uso: sistema construtivo tradicional com estrutura de } \\
\text { concreto armado moldada in loco. }\end{array}$ & \\
\hline \multicolumn{2}{|l|}{ MADEIRA (MA-2) } \\
\hline \multicolumn{2}{|l|}{$\begin{array}{l}\text { Sistema em madeira com tela de proteção. A união dos componentes ocorre mediante } \\
\text { pregos. Os montantes são fixados à superfície da laje mediante barras de ferro de } 8 \\
\text { mm. Uso: sistema construtivo tradicional. }\end{array}$} \\
\hline \multicolumn{2}{|l|}{ METÁLICO (ME-1) } \\
\hline \multirow{2}{*}{\multicolumn{2}{|c|}{$\begin{array}{l}\text { Sistema constituído por módulos metálicos, nas dimensões } 1,50 \times 1,30 \mathrm{~m} \text {. A união dos } \\
\text { módulos ocorre mediante encaixe. A fixação dos montantes ocorre em área grauteada } \\
\text { da alvenaria mediante uma alça de ancoragem, já incorporada ao sistema. Uso: } \\
\text { sistema construtivo em alvenaria estrutural. } \\
\text { METÁLICO (ME-2) }\end{array}$}} \\
\hline & \\
\hline \multirow{2}{*}{\multicolumn{2}{|c|}{$\begin{array}{l}\text { Sistema constituído por módulos metálicos, nas dimensões } 0,80 \text { x } 1,30 \mathrm{~m} \text { e } 1,10 \mathrm{~m} \times \\
1,30 \mathrm{~m} \text {. A união dos módulos ocorre mediante encaixe, travas e pinos de correr. A } \\
\text { fixação dos montantes ocorre na alvenaria grauteada ou viga mediante barra de } \\
\text { ancoragem, já incorporada ao sistema. Uso: sistema construtivo em alvenaria } \\
\text { estrutural e tradicional. } \\
\text { MISTO (MI-1) }\end{array}$}} \\
\hline & \\
\hline \multicolumn{2}{|l|}{$\begin{array}{l}\text { Sistema constituído por travessões e rodapé em madeira com tela de proteção e } \\
\text { montantes metálicos. A união dos elementos horizontais é mediante encaixe nas alças } \\
\text { dos montantes. A fixação à fôrma da viga é do tipo sargento, a qual consiste em } \\
\text { braçadeiras reguláveis acopladas ao montante. Uso: sistema construtivo tradicional. }\end{array}$} \\
\hline \multicolumn{2}{|l|}{ MISTO (MI-2) } \\
\hline \multicolumn{2}{|l|}{$\begin{array}{l}\text { Sistema constituído por travessões e rodapé em madeira com tela de proteção e } \\
\text { montantes metálicos. A união dos elementos horizontais ocorre mediante encaixe nas } \\
\text { alças dos montantes. Os montantes são fixados às escoras das lajes mediante uma } \\
\text { treliça incorporada aos mesmos. Uso: sistema construtivo tradicional. }\end{array}$} \\
\hline \multicolumn{2}{|l|}{ MISTO (MI-3) } \\
\hline \multirow{2}{*}{\multicolumn{2}{|c|}{$\begin{array}{l}\text { Sistema constituído por travessões e rodapé em madeira com tela de proteção e } \\
\text { montantes metálicos. A união dos elementos horizontais é mediante encaixe nas alças } \\
\text { dos montantes. Os montantes são fixados na viga mediante barra de ancoragem, } \\
\text { arruela e porca do tipo borboleta. Uso: sistema construtivo tradicional. }\end{array}$}} \\
\hline & \\
\hline \multicolumn{2}{|l|}{$\begin{array}{l}\text { Sistema constituído por travessões e rodapé em madeira com tela de proteção e } \\
\text { montantes metálicos. A união dos elementos horizontais é mediante encaixe nas alças } \\
\text { dos montantes. Os montantes são fixados à superfície da laje mediante parafusos. } \\
\text { Uso: sistema construtivo tradicional. }\end{array}$} \\
\hline \multicolumn{2}{|l|}{ MISTO (MI-5) } \\
\hline $\begin{array}{l}\text { Sistema constituído por travessões e rodapé em madeira com tela de proteção e } \\
\text { montantes metálicos. A união dos elementos horizontais é mediante encaixe nas alças } \\
\text { dos montantes. Os montantes são fixados na viga mediante barra de ancoragem, } \\
\text { arruela e porca do tipo borboleta. Uso: sistema construtivo tradicional. }\end{array}$ & \\
\hline
\end{tabular}


A Tabela 2 apresenta a quantidade de obras em que cada tipo de SPP foi avaliado. Tais obras correspondem a edifícios residenciais de quatro ou mais pavimentos de sete empresas construtoras de médio e grande porte atuantes na Região Metropolitana de Porto Alegre. Os SPP em madeira e mistos eram comumente utilizados pelas construtoras nas obras com sistema construtivo tradicional. A avaliação deles foi realizada após a retirada das fôrmas, nas fases de montagem e desmontagem, quando já havia a estrutura de concreto armado. Já no sistema de alvenaria estrutural eram utilizados SPP metálicos, e a avaliação foi realizada na única fase em que o sistema era empregado. No total foram realizadas 39 aplicações do protocolo em 26 canteiros de obra, sendo o protocolo em algumas obras aplicado em fases diferentes da construção. A coleta de dados, em cada aplicação do protocolo, teve uma duração média de $4 \mathrm{~h}$ entre observações, medições e entrevistas, envolvendo de dois a três pesquisadores. Em todas as aplicações, inicialmente, foi realizada a avaliação do projeto de SPP conforme a lista de requisitos estabelecidos para essa etapa, seguida da análise em uso em dois pavimentos-tipo em cada obra visitada.

\section{Oportunidades de melhoria}

A partir dos resultados decorrentes das aplicações do protocolo foi realizada uma reunião individual com cada uma das empresas construtoras participantes. Tais reuniões eram integradas por um engenheiro em segurança ou engenheiro responsável pela obra, e por pelo menos um técnico em segurança. Como as empresas construtoras não tinham projetistas de SPP em seus quadros foram realizadas duas reuniões individuais com dois projetistas de SPP que prestam serviços a seis das oito empresas construtoras. As entrevistas individuais foram gravadas e transcritas, tiveram duração média de
$1,5 \mathrm{~h}$ e foram baseadas nos requisitos menos atendidos. A partir das entrevistas buscou-se entender quais as dificuldades das empresas e projetistas em respeitar os requisitos menos atendidos conforme as avaliações. Isso possibilitou identificar oportunidades de aperfeiçoamentos necessários aos SPP.

\section{Resultados}

\section{Avaliação de requisitos de segurança}

O Quadro 3 apresenta os dez requisitos de desempenho quanto à segurança e compara o atendimento aos requisitos de projeto dos diferentes SPP, sendo apresentada uma média das várias obras em que cada sistema é usado. Podese observar que os SPP metálicos (SPP-ME) apresentam maior porcentagem de atendimento que os SPP em madeira (SPP-MA). Por exemplo, os projetos dos SPP-MA não apresentavam a especificação das etapas de montagem, desmontagem e manutenção, bem como os correspondentes riscos. Os projetos de SPP mistos (SPP-MI), embora também não especifiquem etapas de montagem, desmontagem e manutenção, possuem maior grau de detalhe em função do montante pré-fabricado, o qual tem pouca tolerância a irregularidades na execução e a partir do qual são definidas, com maior precisão, especificações tais como quantidade de pregos ou parafusos a serem utilizados na fixação do travessão com o montante e detalhes de reforços ou recortes a serem realizados nos travessões. Um aspecto importante refere-se aos componentes em madeira dos SPP. O requisito 5 estabelece que "o projeto especifica materiais resistentes e duráveis às condições normais de trabalho". Neste caso foi constatado que os SPPMI e SPP-MA atendem parcialmente a este requisito.

Tabela 2 - Quantidade de obras em que cada SPP foi avaliado

\begin{tabular}{l|c|c}
\hline Sistema Construtivo & SPP & Qtde. Obras \\
\hline \multirow{5}{*}{ Tradicional } & MA-1 & 9 \\
& MA-2 & 3 \\
& MI-1 & 2 \\
& MI-2 & 2 \\
& MI-3 & 1 \\
& MI-4 & 2 \\
\multirow{2}{*}{ Alvenaria Estrutural } & MI-5 & 2 \\
\hline \multirow{2}{*}{} & ME-1 & 4 \\
& ME-2 & 1 \\
\hline
\end{tabular}


Quadro 3 - Comparação do atendimento aos requisitos de segurança em projeto

\begin{tabular}{|c|c|c|c|c|c|c|c|c|c|c|c|}
\hline \multirow[b]{2}{*}{ 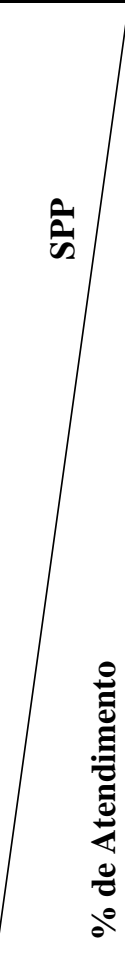 } & \multicolumn{10}{|c|}{ SEGURANÇA - Requisitos de Projeto } & \\
\hline & 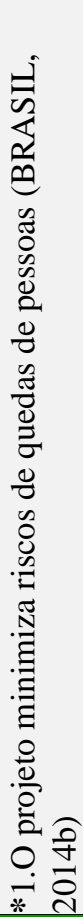 & 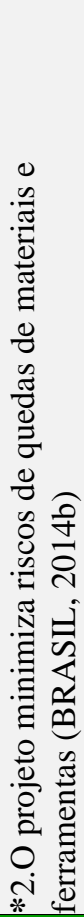 & 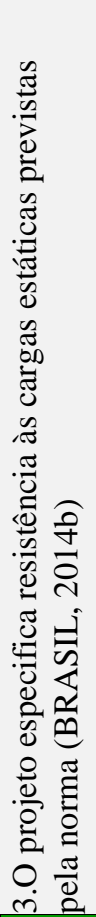 & 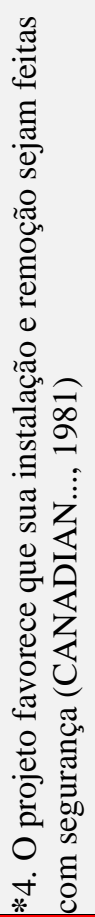 & 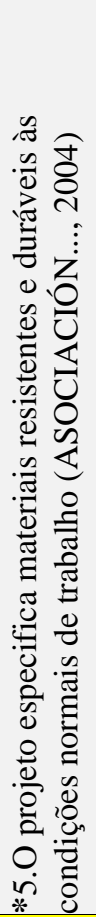 & 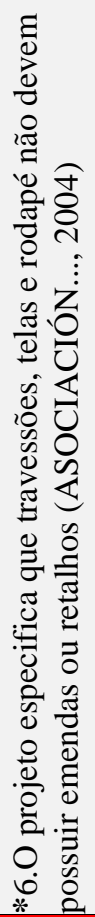 & 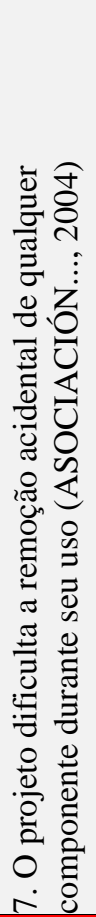 & 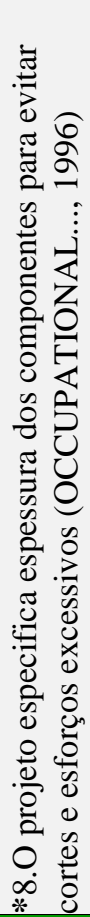 & 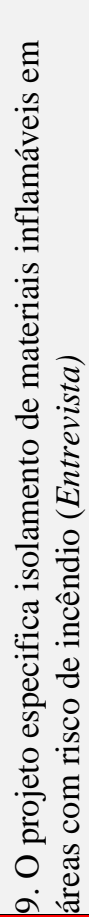 & 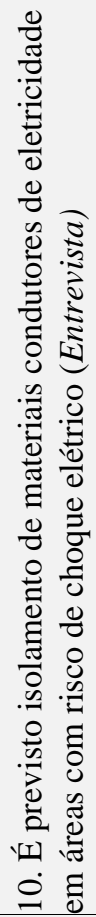 & 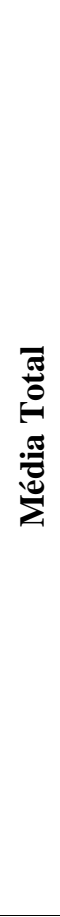 \\
\hline MA-1 & 100 & 100 & 100 & 0 & 50 & 0 & 0 & 100 & 0 & NA & $\mathbf{5 0}$ \\
\hline MA-2 & 100 & 100 & 100 & $\mathbf{0}$ & 50 & $\mathbf{0}$ & $\mathbf{0}$ & 100 & 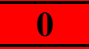 & NA & $\mathbf{5 0}$ \\
\hline MI-1 & 100 & 100 & $\mathbf{0}$ & $\mathbf{0}$ & 50 & $\mathbf{0}$ & 100 & 100 & 0 & 0 & 45 \\
\hline MI-2 & 100 & 100 & 100 & 0 & 50 & 0 & 100 & 100 & 0 & 0 & 55 \\
\hline MI-3 & 100 & 100 & 100 & 0 & 50 & 0 & 100 & 100 & 0 & 0 & 55 \\
\hline MI-4 & 100 & 100 & 0 & 0 & 50 & 0 & 100 & 100 & 0 & 0 & 45 \\
\hline MI-5 & 100 & 100 & 100 & 0 & 50 & 0 & 100 & 100 & 0 & 0 & 55 \\
\hline ME-1 & 100 & 100 & 100 & 100 & 100 & 100 & 100 & NA & NA & 0 & 88 \\
\hline ME-2 & 100 & 100 & 100 & 100 & 100 & 100 & 100 & NA & NA & 0 & 88 \\
\hline
\end{tabular}

Nota: *requisitos aplicáveis tanto na etapa de análise de projeto como na de análise de uso.

Dessa maneira constatou-se que a madeira especificada em todos os projetos (Eucaliptus saligna) não resiste a longos períodos de exposição na periferia da edificação, seja pelas atividades que impactam nela (desforma, carga e descarga de materiais, elevação da alvenaria), seja pelas condições de temperatura e umidade às quais está exposta (Figura 2). A madeira, por ser utilizada em estado natural, normalmente resiste menos ao desgaste às intempéries em comparação a outros materiais tais como metais (METRO..., 2009) e plástico injetado (SECURITY..., 2008). Os projetos não especificam a vida útil do material, e muitas vezes a madeira é reutilizada na mesma obra sem uma inspeção rigorosa, reduzindo a resistência e comprometendo o desempenho do SPP. Segundo um dos projetistas de SPP entrevistado, as empresas que optam pela madeira levam em conta o baixo custo de aquisição e a facilidade de descarte, o que é vantajoso quando a empresa não possui espaço físico para o armazenamento para futuro reaproveitamento dos componentes. Além disso, a identificação dos componentes (por exemplo, com etiqueta apontando a data de uso inicial) ajudaria os trabalhadores a ter melhor controle e rastreabilidade sobre as peças utilizadas nos SPP, possibilitando melhor reutilização.

O Quadro 4 apresenta onze requisitos de desempenho quanto à segurança e compara as médias de atendimento de uso dos SPP-MA com os SPP-MI e SPP-ME. Na fase de estrutura os SPP podem permanecer semanas ou meses na periferia da edificação, sendo retirados somente quando a alvenaria de vedação periférica atingir a altura de 1,0 m ou mais. Contudo, ao comparar os SPP-MA e SPP-MI com os SPP-ME, pode-se observar que os SPP-ME apresentam o maior atendimento aos requisitos de uso. Por exemplo, seis dos oito SPP-MA-1 avaliados atendiam 
parcialmente ao requisito 5 (a instalação e a remoção do SPP devem ser feitas com segurança). Nessa situação o atendimento parcial devia-se à falta ou uso incorreto de EPIs, ao uso de ferramentas e equipamentos inadequados, em muitos casos à falta de informação sobre as ferramentas e equipamentos adequados e disponíveis para realizar a tarefa, bem como à ausência de definição de uma sequência de montagem e desmontagem.

Uma das situações de maior risco durante a montagem dos SPP é a instalação dos montantes, pois estes componentes são difíceis de manipular (requisito de flexibilidade) e os trabalhadores geralmente ficam com parte do corpo exposto para fora da periferia. Isso vale tanto para os SPP-MA-1 como para os SPP-MI-1 e SPP-MI-3. As deficiências de concepção dos SPP contribuem para atitudes inseguras dos operários, tais como segurar nas escoras para não perder o equilíbrio, utilizar escadas sem proteção, posicionar-se sobre as plataformas de proteção ou sobre o rodapé para fixá-lo, como ilustrado na Figura 3.

Figura 2 - (a) e (b) SPP-MA e (c) e (b) rachaduras no rodapé e desprendimento do travessão superior SPP-MI

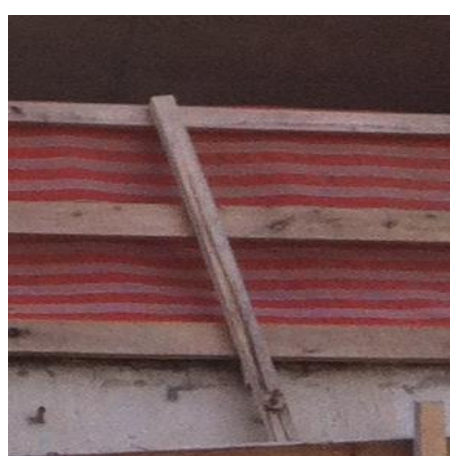

(a) Rachadura no montante e perda da estabilidade

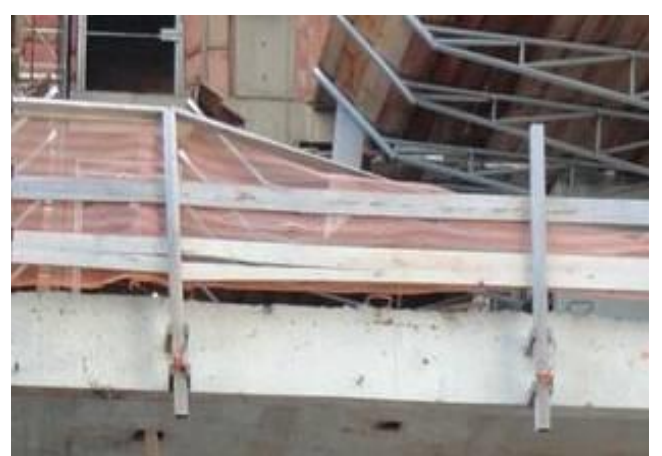

(b) Rachaduras no rodapé e desprendimento do travessão superior

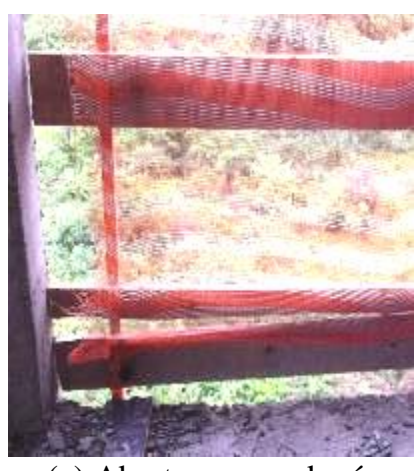

(c) Abertura no rodapé

Quadro 4 - Comparação do atendimento aos requisitos de segurança em uso

\begin{tabular}{|c|c|c|c|c|c|c|c|c|c|c|c|c|}
\hline \multirow[b]{2}{*}{ के } & \multicolumn{11}{|c|}{ SEGURANÇA - Requisitos de Uso } & \multirow[b]{2}{*}{ 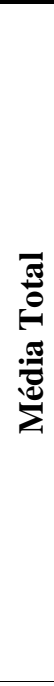 } \\
\hline & 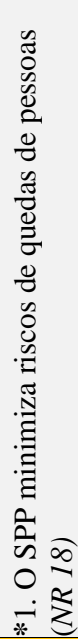 & 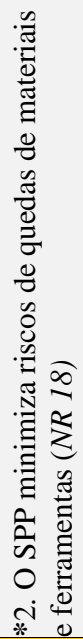 & 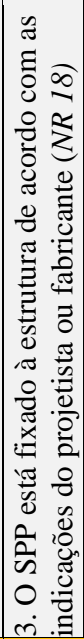 & $\begin{array}{l}0 \\
\vdots \\
0 \\
0 \\
0 \\
0 \\
0 \\
0 \\
0 \\
0 \\
0 \\
0 \\
0 \\
0 \\
0 \\
0 \\
0 \\
0 \\
0 \\
0 \\
0 \\
0 \\
0 \\
0 \\
0 \\
0 \\
0 \\
0 \\
0 \\
0 \\
0\end{array}$ & 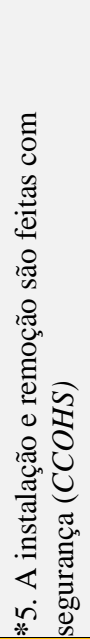 & 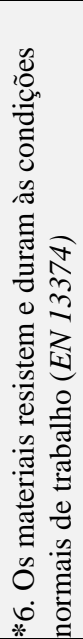 & 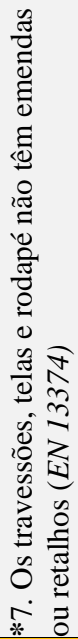 & 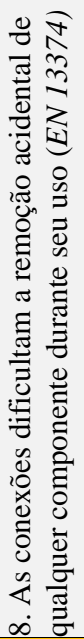 & 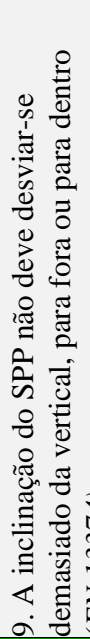 & 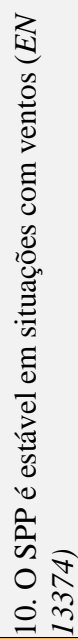 & 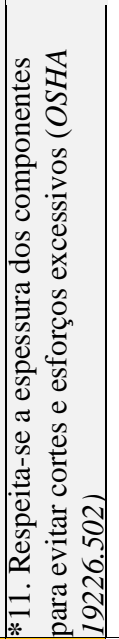 & \\
\hline MA-1 & 62 & 57 & 63 & 79 & 66 & 73 & 60 & 73 & 100 & 95 & $7 \overline{5}$ & 73 \\
\hline MA-2 & 73 & 96 & 100 & 100 & 75 & 87 & 90 & 78 & NA & 97 & 67 & 86 \\
\hline MI-3 & 88 & 50 & 50 & 87 & 92 & 94 & 81 & 50 & 87 & 97 & 100 & 75 \\
\hline MI-4 & 100 & 87 & 100 & 92 & 75 & 84 & 87 & 50 & 100 & 95 & 100 & 88 \\
\hline MI-5 & 100 & 68 & 100 & 81 & 100 & 69 & 78 & 50 & 100 & 90 & 100 & 85 \\
\hline ME-1 & 100 & 0 & 100 & 100 & 100 & 97 & 100 & 100 & 100 & 100 & NA & 90 \\
\hline ME-2 & 100 & 0 & 0 & 100 & 100 & 100 & 100 & 100 & 100 & 100 & NA & 80 \\
\hline
\end{tabular}

Nota: *requisitos aplicáveis tanto na etapa de análise de projeto como na de análise de uso. 
Figura 3 - Exemplo de atendimento parcial ao requisito 5 - montagem SPP-MA-1

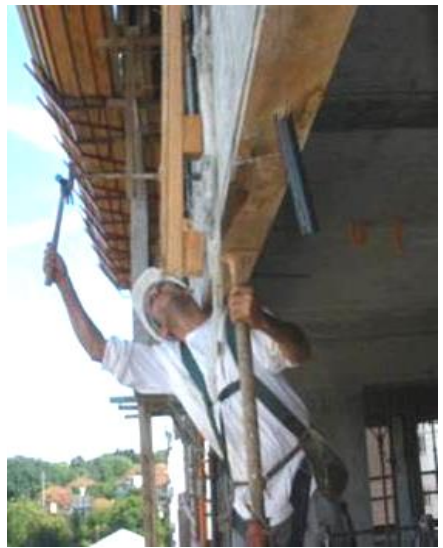

(a)

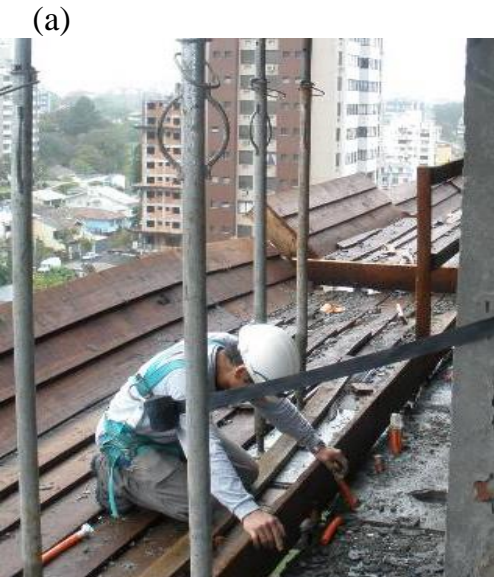

(d)

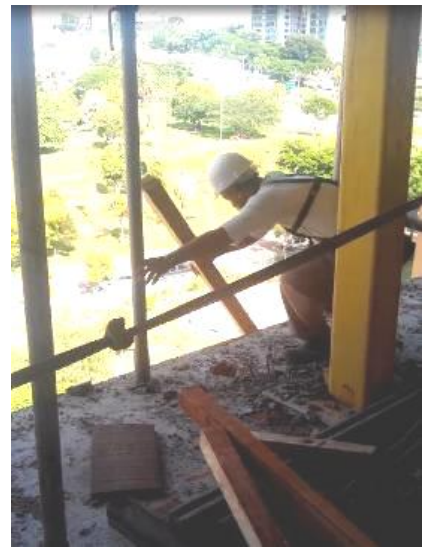

(b)

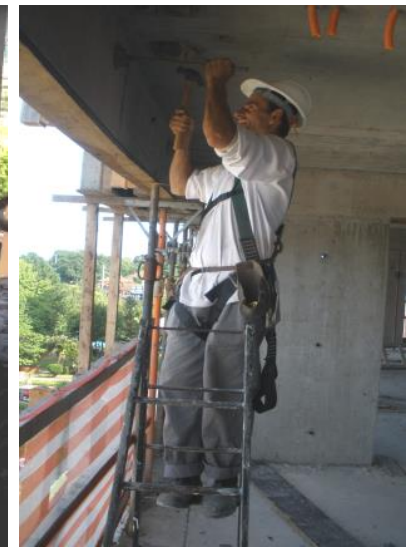

(c)

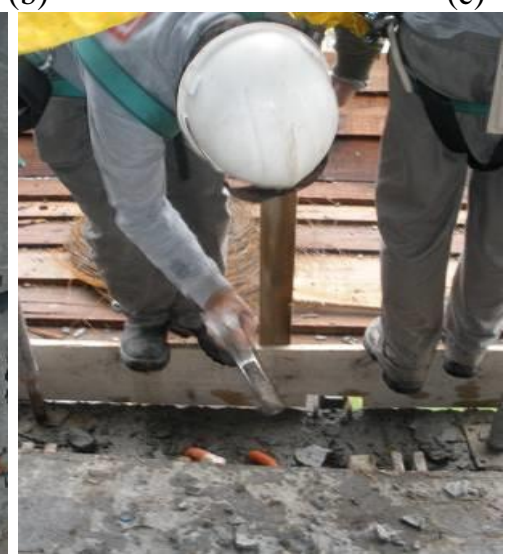

(e)

Um exemplo de boa prática no atendimento ao requisito 5 foi observado com o SPP-MI-5, concebido para garantir proteção ao trabalhador sem necessidade de cinto de segurança. Neste caso, as vigas de periferia foram pré-fabricadas, e a instalação do SPP-MI-5 ocorreu no térreo, em área isolada e devidamente sinalizada (Figura 4a). Após a instalação, as vigas com os SPP-MI-5 já fixados foram içadas mediante guindaste até seu respectivo pavimento (Figura 7b). $\mathrm{Na}$ desmontagem deles também foram respeitadas as medidas de segurança, uma vez que as ferramentas e equipamentos empregados eram adequados à tarefa, tal como o uso de escada com guarda-corpo no patamar de trabalho (Figura 4c, 4d).

Outro exemplo positivo de atendimento ao requisito 5 refere-se ao SPP-ME-2 analisado no sistema de alvenaria estrutural, que também pode ser utilizado para sistemas construtivos tradicionais. Tal sistema possui um manual que descreve os componentes do SPP e apresenta, passo a passo, o processo de montagem $\mathrm{e}$ desmontagem, bem como os EPIs e ferramentas a serem utilizados. Neste caso não é necessário o uso de cinto de segurança, já que o SPP-ME garante proteção aos trabalhadores não só na elevação da alvenaria, à medida que a edificação for subindo (Figura 5a), bem como na montagem e desmontagem do SPP (Figura 5b).

\section{Avaliação de requisitos de eficiência}

O Quadro 5 apresenta os requisitos de eficiência dos SPP e compara o atendimento a estes requisitos na fase de projeto. Mais uma vez os SPP-ME obtiveram maior grau de atendimento em comparação com os SPP-MI e SPP-MA. Isso se deve principalmente aos mecanismos de conexão entre componentes, tais como encaixes, travas e pinos, que facilitam a montagem e desmontagem. Tais mecanismos evitam esforços excessivos ao mesmo tempo em que aumentam a produtividade. Além disso, os componentes de conexão integrados ao montante, e este, por sua vez, integrado às telas modulares, diminuem a variedade e quantidade de componentes, além de reduzir a quantidade de manuseios durante o transporte, diminuindo em consequência a exposição dos trabalhadores aos riscos nessa atividade. 
Figura 4 - SPP-MI-5 - exemplo de atendimento ao requisito 5

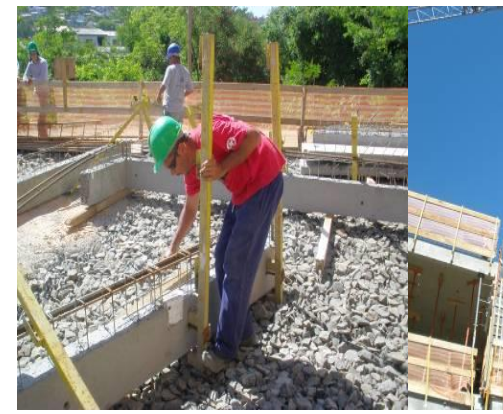

(a)

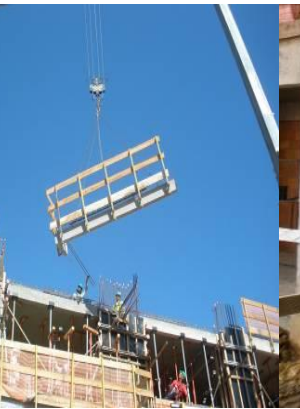

(b)

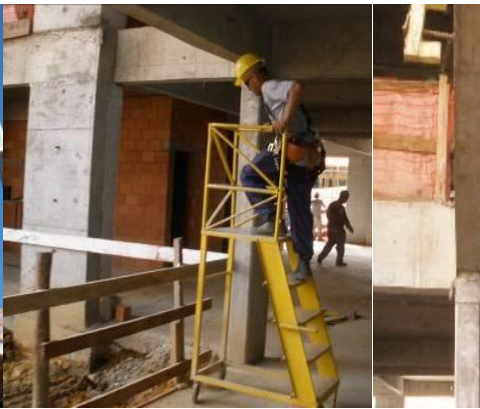

(c)

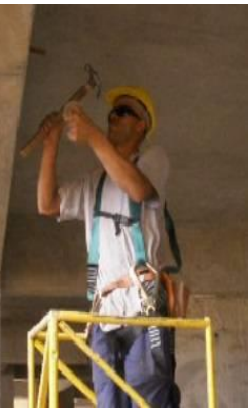

(d)

Figura 5 - SPP-ME-2 - exemplo de atendimento ao requisito 5

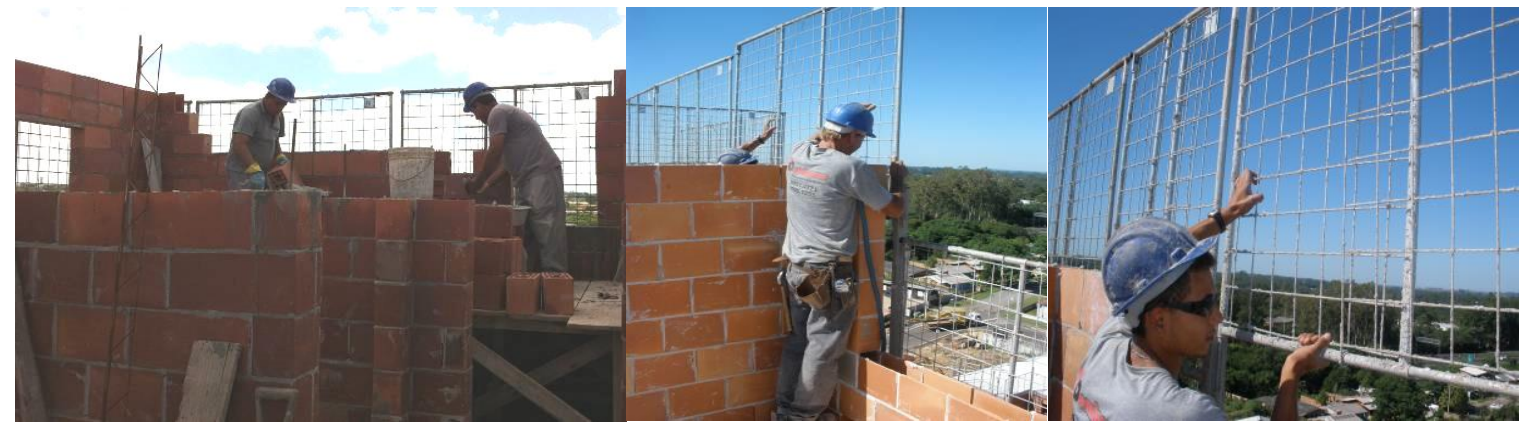

Quadro 5 - Comparação do atendimento aos requisitos de eficiência em projeto

\begin{tabular}{|c|c|c|c|c|c|c|c|}
\hline \multirow[b]{2}{*}{$\hat{\sigma}$} & \multicolumn{6}{|c|}{ EFICIÊNCIA - Requisitos de Projeto } & \\
\hline & 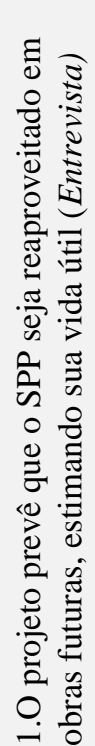 & 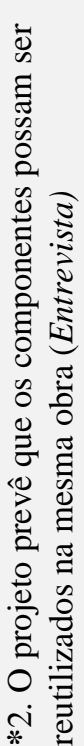 & 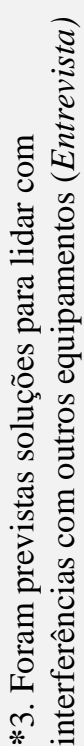 & 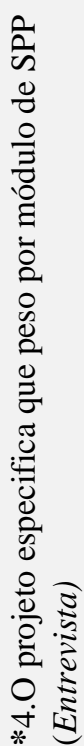 & 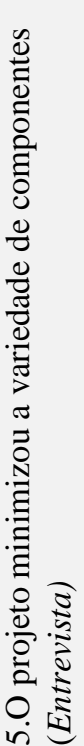 & 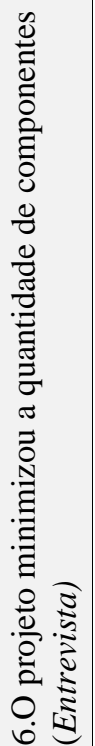 & 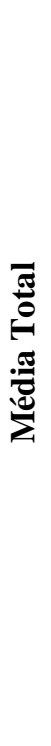 \\
\hline MA-1 & 0 & 100 & 0 & 0 & 0 & 0 & 16 \\
\hline MA-2 & 0 & 100 & $\mathbf{0}$ & $\mathbf{0}$ & 0 & 0 & 16 \\
\hline MI-1 & 50 & 50 & 0 & $\mathbf{0}$ & 100 & $\mathbf{0}$ & 33 \\
\hline MI-2 & 50 & 50 & 100 & $\mathbf{0}$ & 100 & $\mathbf{0}$ & 50 \\
\hline MI-3 & 50 & 50 & 0 & $\mathbf{0}$ & $\mathbf{0}$ & 0 & 16 \\
\hline MI-4 & 50 & 50 & $\mathbf{0}$ & $\mathbf{0}$ & 100 & $\mathbf{0}$ & 33 \\
\hline MI-5 & 50 & 50 & 0 & 0 & 100 & 0 & 33 \\
\hline ME-1 & 100 & 100 & 100 & 0 & 100 & 100 & 83 \\
\hline ME-2 & 100 & 100 & 100 & 0 & 100 & 100 & 83 \\
\hline
\end{tabular}

Nota: *requisitos aplicáveis tanto na etapa de análise de projeto como na de análise de uso. 
O Quadro 6 compara a porcentagem de atendimento aos requisitos de uso. Destaca-se que doze dos dezoito SPP-MA avaliados não atenderam ao requisito 7 (reduzir o esforço físico nas atividades de montagem do SPP). Para a análise deste requisito foi adotado o critério de Percentual Máximo de Frequência Cardíaca (PMFC), considerado como equivalente ao percentual da capacidade aeróbica máxima utilizada. Esse porcentual é calculado da seguinte forma: $\mathrm{PMFC}=\left(\mathrm{FC}_{\text {média }}-\mathrm{FC}_{\text {repouso }}\right) /\left(\mathrm{FC}_{\text {máxima }}\right.$ esperada $\left.-\mathrm{FC}_{\text {repouso }}\right)$. De acordo com Kodack (1983) e Rodgers (1986), pode-se considerar que $33 \%$ é o limite aceitável do percentual da máxima capacidade aeróbica utilizada. O SPP-MA-1 e o SPP-MA-2 são exemplos de não atendimento ao dito requisito, visto que o PMFC foi de $34 \%$ e de
36\% (acima do máximo) em comparação com os SPP-MI e SPP-ME que obtiveram um valor abaixo do máximo permitido. Por exemplo, o SPP-MI-5 obteve $28 \%$, enquanto no SPP-ME-2 o PMFC foi de $18 \%$. Tais dados correspondem à média dos PMFC de dois trabalhadores durante 30 min. Da mesma maneira, ao analisar a carga postural dos SPP-MA, a postura de pé apoiado sobre os dois joelhos curvados ocorreu em $75 \%$ das observações, estando então na categoria de risco 4 (risco alto), conforme o método OWAS (Figura 6). Já a postura de costas curvadas encontra-se no limite da categoria de risco 2 (risco médio), existindo em $75 \%$ das observações. As posturas desfavoráveis de costas e joelhos devem-se principalmente à fixação de peça por peça mediante pregos (Figura 7).

Quadro 6 - Comparação do atendimento aos requisitos de eficiência em uso

\begin{tabular}{|c|c|c|c|c|c|c|c|c|c|c|c|c|}
\hline \multirow[b]{2}{*}{ 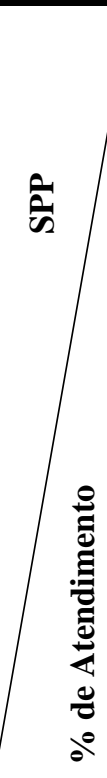 } & \multicolumn{11}{|c|}{ EFICIÊNCIA - Requisitos de Uso } & \\
\hline & 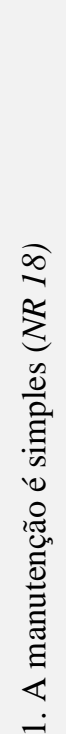 & 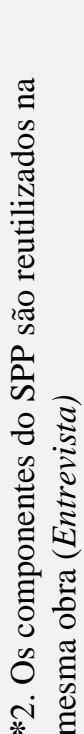 & 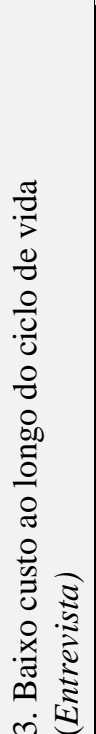 & 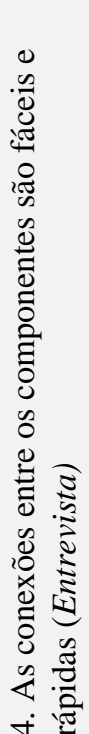 & 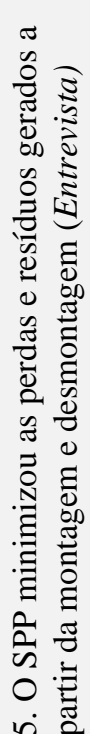 & 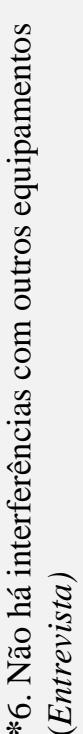 & 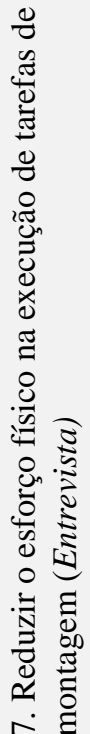 & 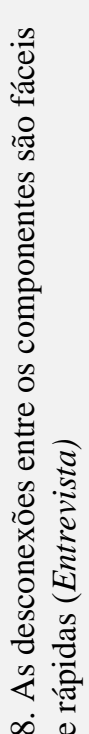 & 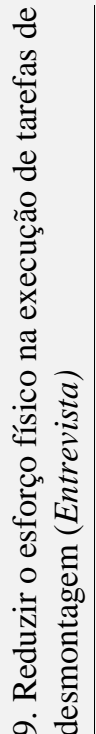 & 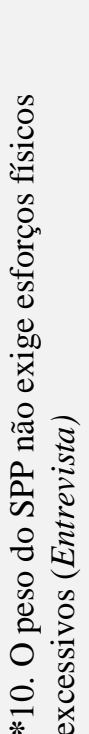 & 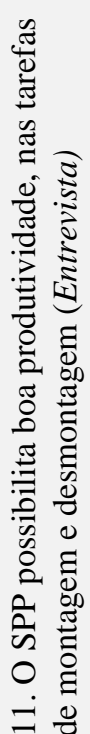 & 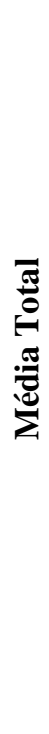 \\
\hline MA-1 & 100 & 100 & 0 & 0 & 0 & 50 & 0 & 50 & 50 & 50 & 0 & 36 \\
\hline MA-2 & 100 & $\mathbf{0}$ & $\mathbf{0}$ & 0 & $\mathbf{0}$ & 50 & $\mathbf{0}$ & 50 & 50 & NA & $\mathbf{0}$ & 22 \\
\hline MI-1 & $\mathbf{5 0}$ & 100 & 50 & 100 & 50 & 50 & 100 & 100 & 100 & 100 & 100 & 81 \\
\hline MI-2 & 100 & 100 & 50 & 100 & 50 & 100 & 100 & 100 & 100 & 100 & 100 & 91 \\
\hline MI-3 & 50 & 100 & 50 & 50 & 50 & 50 & 100 & 100 & 100 & 100 & 0 & 68 \\
\hline MI-4 & 50 & 100 & 50 & 50 & 50 & 50 & 100 & 100 & 100 & 100 & 100 & 77 \\
\hline MI-5 & 50 & 100 & 50 & 100 & 50 & 50 & 100 & 100 & 100 & 100 & 100 & 81 \\
\hline ME-1 & 50 & 100 & 100 & 50 & 100 & 100 & 100 & 100 & 100 & 50 & 100 & 86 \\
\hline ME-2 & 50 & 100 & 100 & 100 & 100 & 100 & 100 & 100 & 100 & 100 & 100 & 95 \\
\hline
\end{tabular}

Nota: *requisitos aplicáveis tanto na etapa de análise de projeto como na análise de uso. 
Figura 6 - Gráfico das posturas analisadas com WinOWAS na montagem dos SPP-MA-1

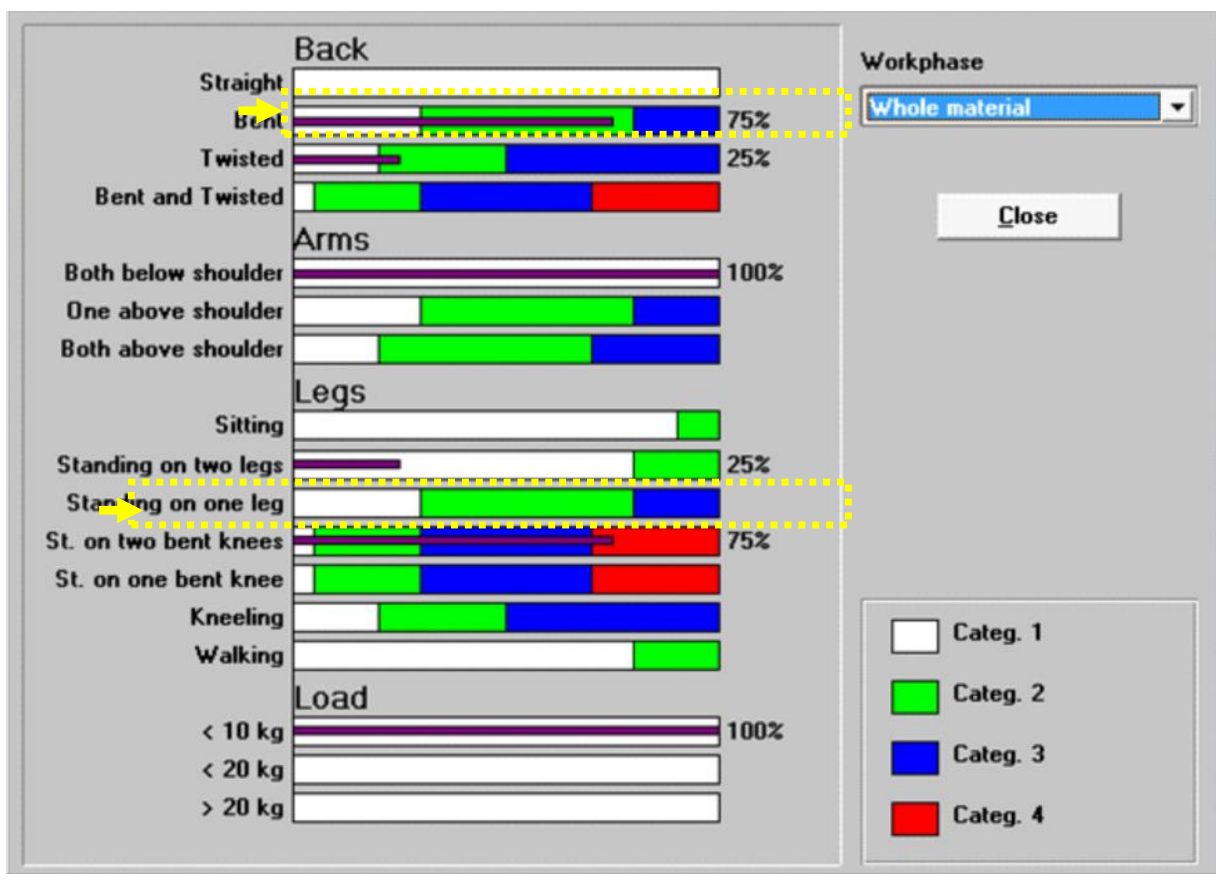

Figura 7 - Posturas de pé, apoiado sobre os dois joelhos curvados e costas curvadas

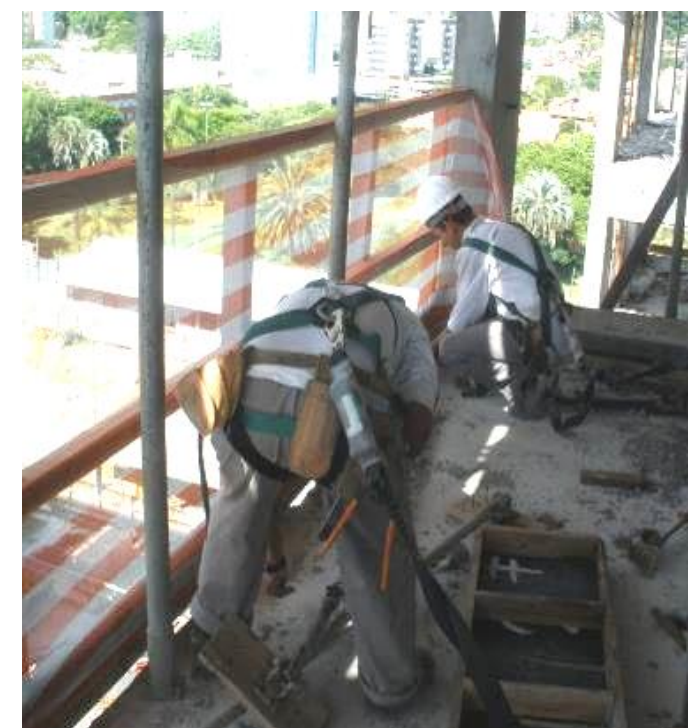

(a) Fixação do componente rodapé do SPP-MA-1
No caso dos SPP-MI-5, a postura de pé com as costas curvadas ocorreu em 59\% das observações e se encontra na categoria de risco 3 (médio-alto) (Figura 8). Essa postura desfavorável (ver Figura 9) pode ser corrigida, por exemplo, mediante um apoio ou bancada para posicionar as vigas.

Os SPP-ME em geral apresentam baixo PMFC. Isso se deve principalmente a mecanismos de conexão simples, como travas e encaixes entre uma pequena quantidade de componentes (tela,

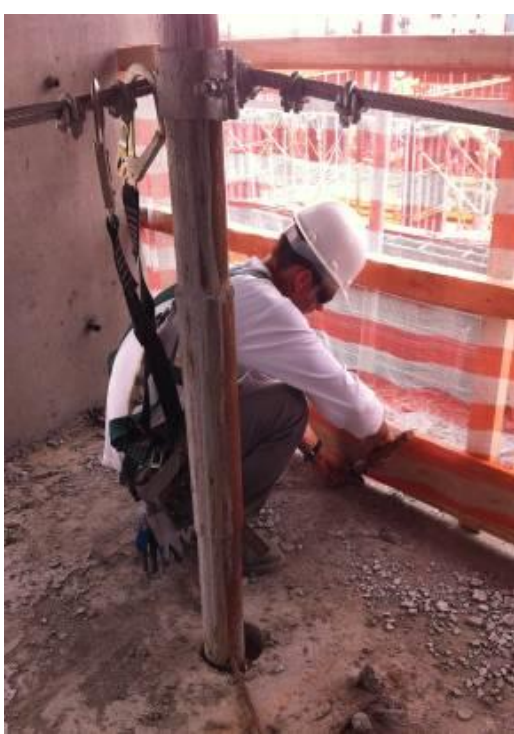

(b) Fixação da tela de proteção do SPP-MA2

montante, rodapé) sem exigir esforços excessivos. No que diz respeito às posturas, em ambos SPP-ME avaliados verificou-se que a posição mais crítica é aquela que implica manter um braço acima do ombro, o que ocorreu em $56 \%$ das observações (Figura 10). Essa postura encontra-se na categoria de risco 2 segundo o método OWAS e durou em média $3 \mathrm{~s}$, devido à agilidade de instalação do sistema (Figura 11). 
Figura 8 - Gráfico das posturas analisadas com WinOWAS na montagem de SPP-MI-5

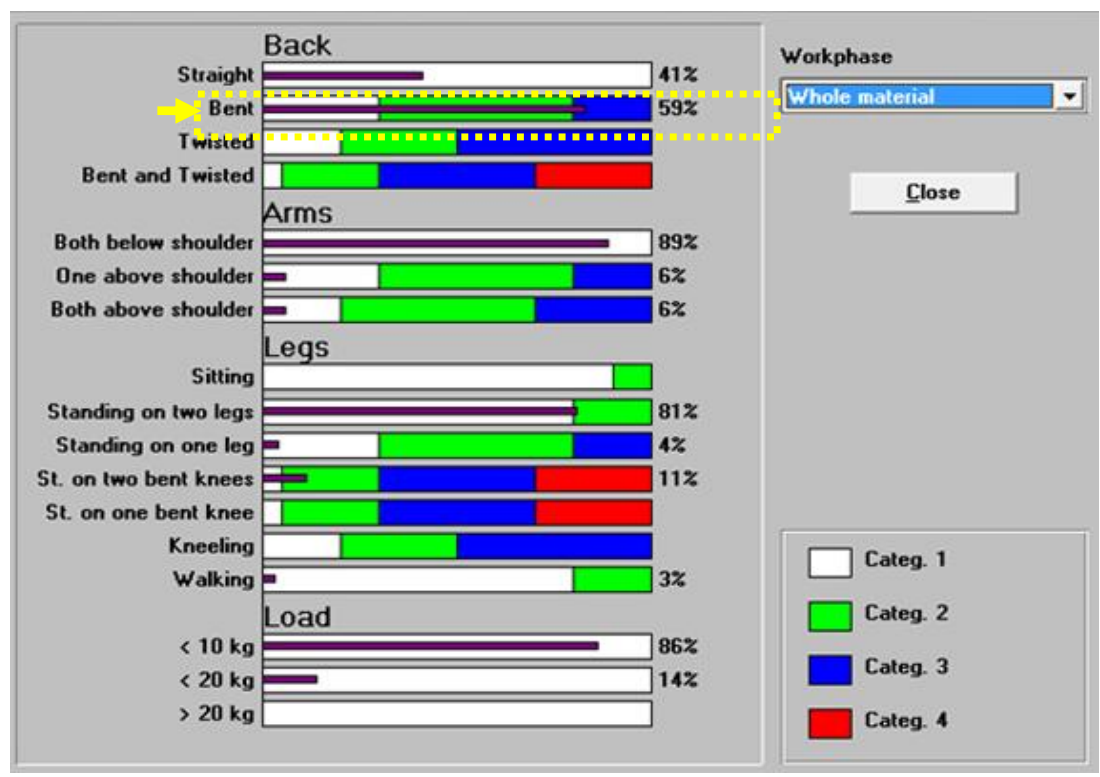

Figura 9 - (a) Montagem do montante do SPP MI-5; e (b) corte do componente rodapé do SPP MI-5

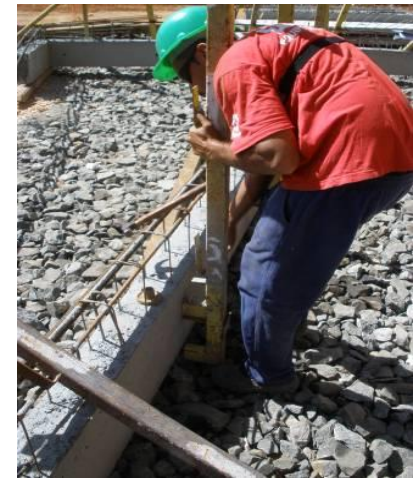

(a)

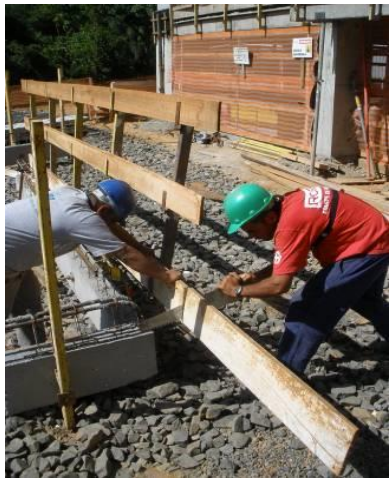

(b)

Figura 10 - Gráfico das posturas analisadas com WinOWAS na montagem e desmontagem dos SPP-ME-2

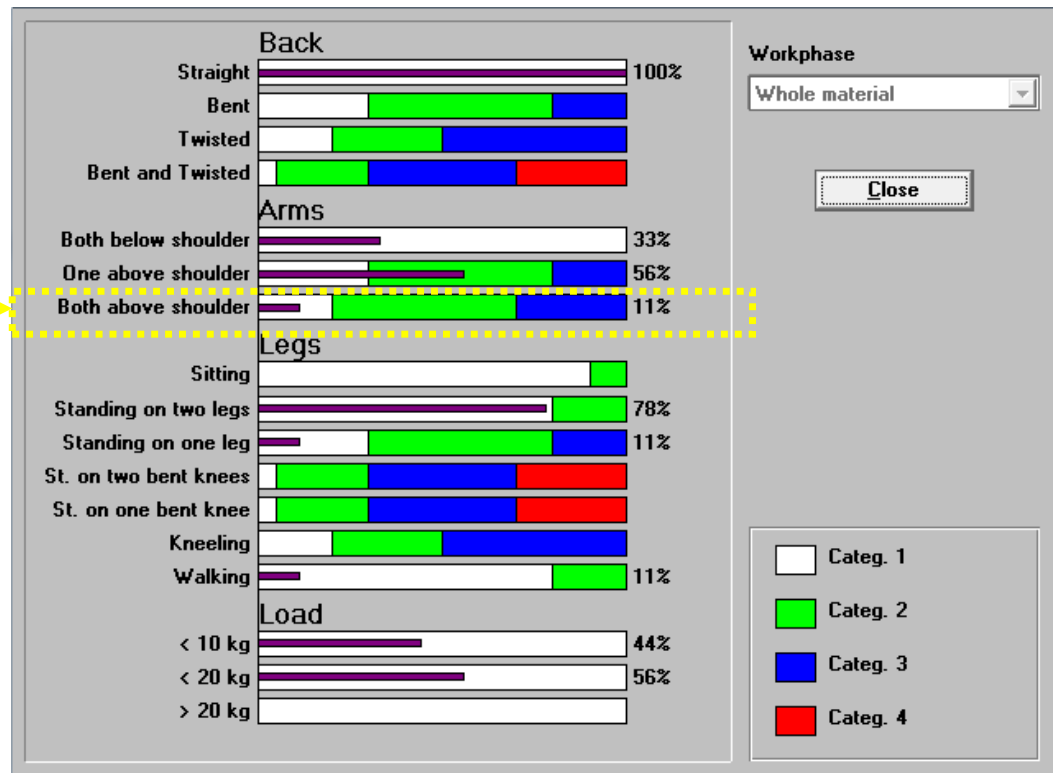


Figura 11 - Postura de braço acima do ombro

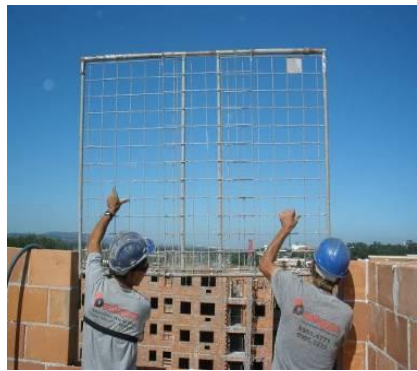

(a) Encaixe das telas aos montantes do SPP-ME-2

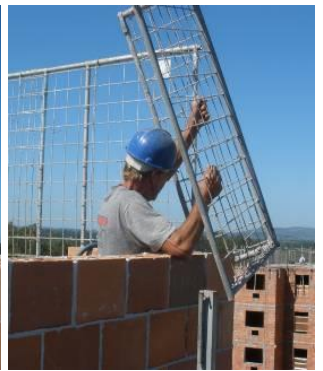

(b) Encaixe das telas aos montantes do SPP-ME-2

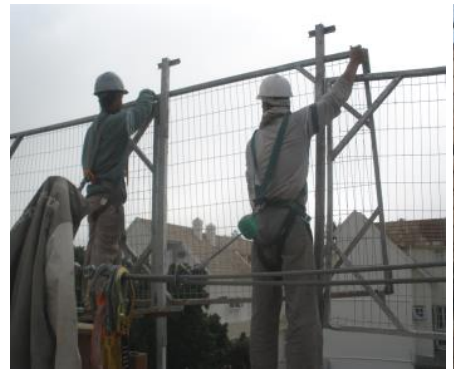

(c) Desmontagem da tela do SPP-ME-1

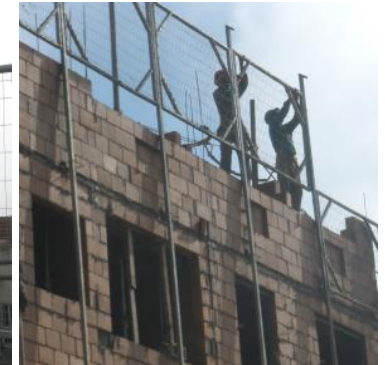

(d) Encaixe da tela aos montantes do SPP-ME-

Quadro 7 - Comparação do atendimento aos requisitos de flexibilidade em projeto

\begin{tabular}{|c|c|c|c|c|c|c|c|}
\hline \multirow[b]{2}{*}{ के } & \multicolumn{6}{|c|}{ FLEXIBILIDADE - Requisitos de Projeto } & \multirow[b]{2}{*}{ 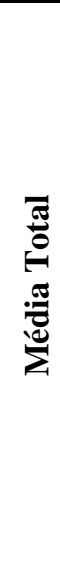 } \\
\hline & 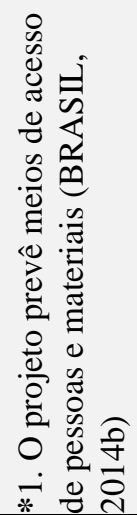 & 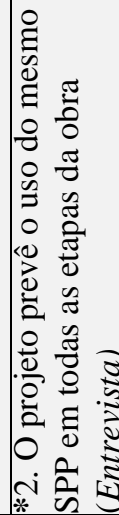 & 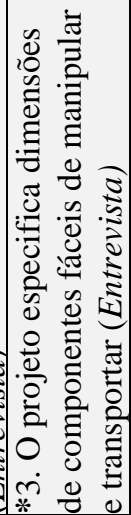 & 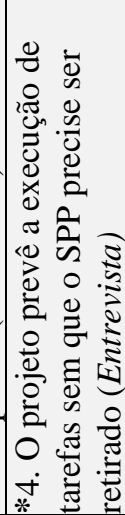 & 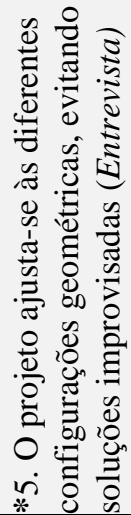 & 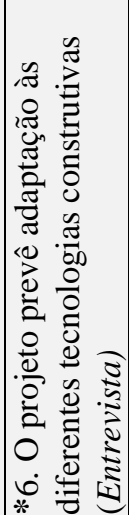 & \\
\hline MA-1 & 0 & 100 & 50 & 100 & 100 & 0 & 58 \\
\hline MA-2 & $\mathbf{0}$ & $\mathbf{0}$ & 100 & $\mathbf{0}$ & $\mathbf{0}$ & $\mathbf{0}$ & 16 \\
\hline MI-1 & $\mathbf{0}$ & $\mathbf{0}$ & 100 & $\mathbf{0}$ & 100 & $\mathbf{0}$ & 33 \\
\hline MI-2 & 0 & 0 & 100 & 100 & 100 & $\mathbf{0}$ & $\mathbf{5 0}$ \\
\hline MI-3 & $\mathbf{0}$ & 100 & $\mathbf{0}$ & 100 & 100 & $\mathbf{0}$ & 50 \\
\hline MI-4 & 0 & 0 & 100 & 0 & 100 & 0 & 33 \\
\hline MI-5 & 0 & 100 & 100 & 100 & 100 & 0 & 66 \\
\hline ME-1 & 100 & 100 & 50 & 100 & 100 & 0 & 75 \\
\hline ME-2 & 100 & 100 & 100 & 100 & 100 & 0 & 83 \\
\hline
\end{tabular}

Nota: *requisitos aplicáveis tanto na etapa de análise de projeto como na de análise de uso.

\section{Avaliação de requisitos de flexibilidade}

Os resultados indicaram que os SPP-ME têm melhor desempenho em relação à flexibilidade, ao ajustarem-se a todas as etapas da obra bem como às diferentes configurações geométricas (Quadro 7). Por exemplo, os montantes e quadros metálicos dos SPP-ME-2 são reguláveis em comprimento e articuláveis, o que permite melhor adaptação à periferia da edificação (Figura 12).

Nos SPP-MA e SPP-MI, o principal aspecto de flexibilidade a salientar é a adaptação a diferentes configurações geométricas, uma vez que os componentes em madeira podem ser recortados e acoplados entre si, de forma a ajustar o SPP a situações específicas ou inesperadas, somente detectadas no canteiro de obras. No caso dos SPP-ME, o projeto é adaptado a cada obra em particular em função dos diferentes módulos que compõem o SPP.

O Quadro 8 compara o atendimento aos requisitos de flexibilidade na fase de uso. Um aspecto a salientar refere-se aos SPP-MA-1, SPPMI-3 e SPP-MI-5, os quais foram atendidos no projeto, mas não no uso, como ocorreu com o requisito 4 (o SPP permite a execução de tarefas sem precisar ser retirado, eliminando o cinto de segurança). Embora tais SPP estejam um pouco projetados para fora da periferia, o que permite a 
elevação da alvenaria de vedação externa, algumas empresas optam por remover o SPP antes ou durante a elevação da alvenaria, enquanto outras preferem manter o SPP instalado até finalizar as tarefas, requerendo uso de meios para removê-lo, tais como andaimes suspensos. Esta última situação gera riscos adicionais, já que muitas vezes ficam isolados em locais inacessíveis, podendo cair e atingir os trabalhadores no nível do solo (Figura 13). Por outro lado, nos SPP-ME os projetos em geral não preveem meios de acesso de pessoas e materiais a partir da periferia (requisito 1). Já na análise em uso dos SPP-ME-1 percebeu-se que foram incorporados pontos de acesso que facilitam o ingresso de pessoas e materiais por meio de módulos com portas do tipo cancela ou portões (Figura 14).

Figura 12 - Aspectos de flexibilidade do SPP-ME-2

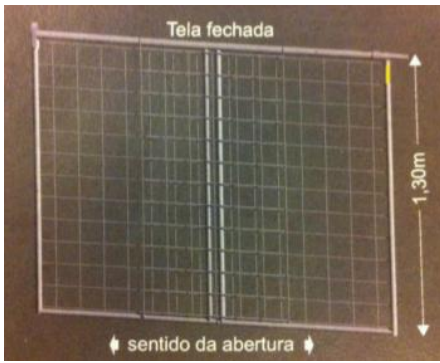

(a) Telas reguláveis em cumprimento

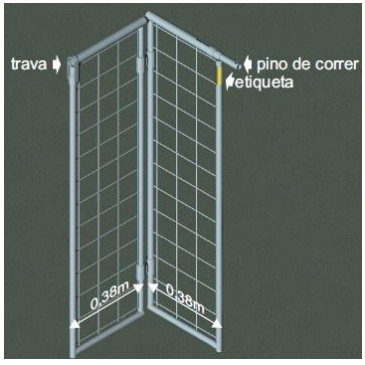

(b) Telas articuláveis em quina

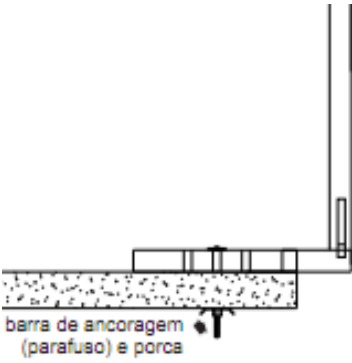

(c) Montante laje em balanço

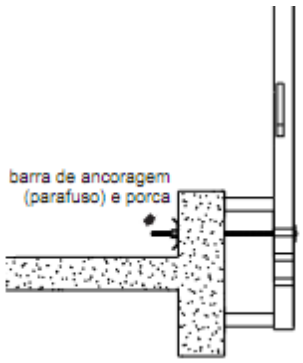

(d) Montante viga de periferia/alvenaria

Fonte: Scanmetal (2011).

Quadro 8 - Comparação do atendimento aos requisitos de flexibilidade em uso

\begin{tabular}{|c|c|c|c|c|c|c|c|}
\hline \multirow[b]{2}{*}{ के } & \multicolumn{6}{|c|}{ FLEXIBILIDADE - Requisitos de Uso } & \\
\hline & 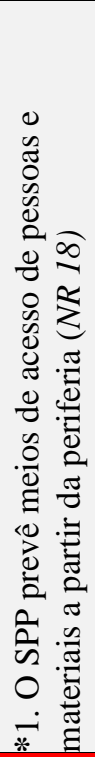 & 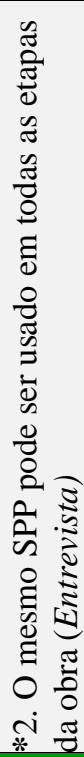 & 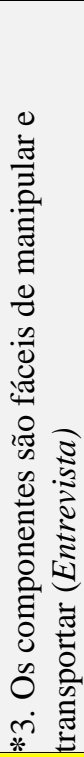 & 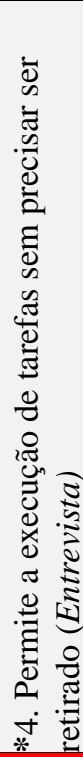 & 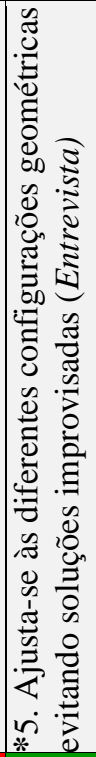 & 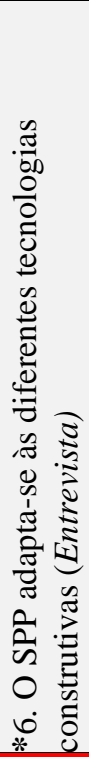 & 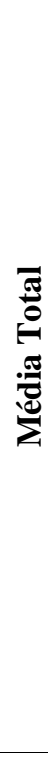 \\
\hline MA-1 & 0 & 100 & 50 & 0 & 100 & 0 & 50 \\
\hline МA-2 & $\mathbf{0}$ & $\mathbf{0}$ & 50 & $\mathbf{0}$ & 100 & $\mathbf{0}$ & 25 \\
\hline MI-1 & $\mathbf{0}$ & 0 & 50 & 100 & 100 & $\mathbf{0}$ & 42 \\
\hline MI-2 & $\mathbf{0}$ & $\mathbf{0}$ & 50 & 100 & 100 & $\mathbf{0}$ & 42 \\
\hline MI-3 & $\mathbf{0}$ & 100 & 0 & $\mathbf{0}$ & 50 & $\mathbf{0}$ & 25 \\
\hline MI-4 & $\mathbf{0}$ & $\mathbf{0}$ & 50 & $\mathbf{0}$ & 100 & $\mathbf{0}$ & 25 \\
\hline MI-5 & 0 & 0 & 50 & 0 & 100 & 0 & 42 \\
\hline ME-1 & 100 & 100 & 100 & 100 & 100 & 0 & 83 \\
\hline ME-2 & 0 & 100 & 100 & 100 & 100 & 0 & 66 \\
\hline
\end{tabular}

Nota: *requisitos aplicáveis tanto na etapa de análise de projeto como na de análise de uso do SPP. 
Figura 13 - (a) Remoção do SPP-MA-1 antes da vedação vertical; (b) SPP-MA-1 após vedação vertical; (c) remoção do SPP-MI-5 antes da vedação vertical; e (d) SPP- MI-5 após vedação vertical

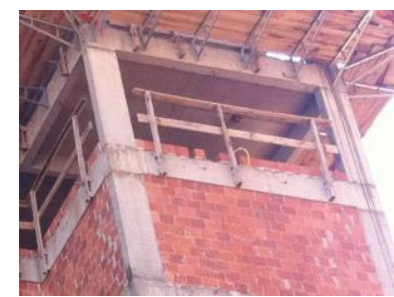

(a)

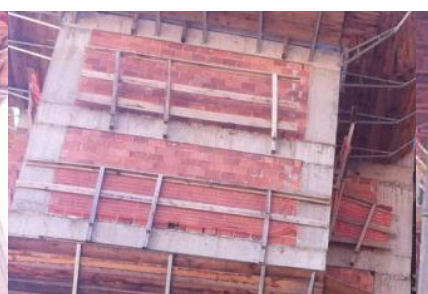

(b)

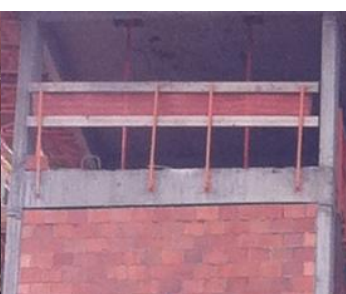

(c)

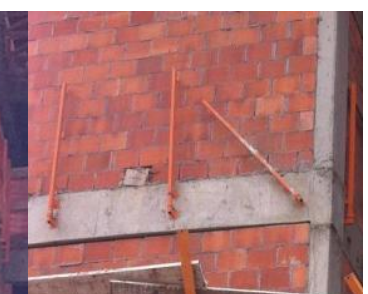

(d)

Figura 14 - SPP-ME-1 - exemplo de atendimento ao requisito 1

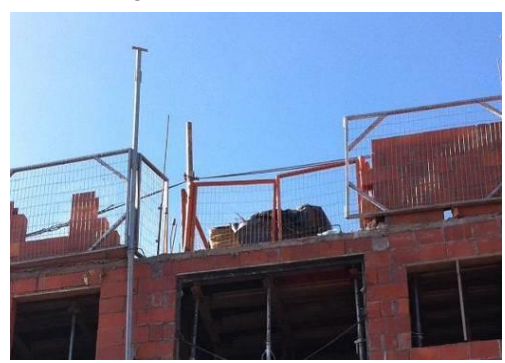

\section{Síntese da análise}

A Figura 15 sintetiza a média total de atendimento por categoria de cada SPP avaliado. Dos nove tipos diferentes de SPP os SPP-MA obtiveram o desempenho mais baixo nas três categorias. Por outro lado, os SPP-ME apresentaram melhor desempenho à segurança, eficiência e flexibilidade em comparação com os SPP-MA e SPP-MI. Pode-se observar que na categoria segurança os SPP-ME superam em $25 \%$ os SPP-MA e SPP-MI, e tiveram um resultado $67 \%$ mais elevado na categoria eficiente que os SPP-MA e 33\% que os SPP-MI. Já na categoria flexibilidade os SPP-ME ultrapassam os SPP-MA e SPP-MI em $40 \%$. Por sua vez, os SPP-MI apresentam melhor desempenho à eficiência que os SPP-MA, mas o desempenho em relação à segurança e flexibilidade resulta similar em alguns casos, como, por exemplo, SPP-MA-1 e SPP-MI-5 ou SPP-MA-2 e SPP-MI-4. Isso se deve ao fato de que estes SPP possuem características semelhantes, tais como componentes, dimensões e capacidade de adaptação ao local de trabalho.

\section{Oportunidades de melhoria nos SPP}

Foram identificados exemplos de SPP disponíveis no mercado nacional e internacional que apresentam soluções que contribuem para um melhor desempenho dos SPP avaliados. Na categoria segurança foi salientado o baixo atendimento ao requisito 5: a instalação e a remoção do SPP devem ser feitas com segurança.

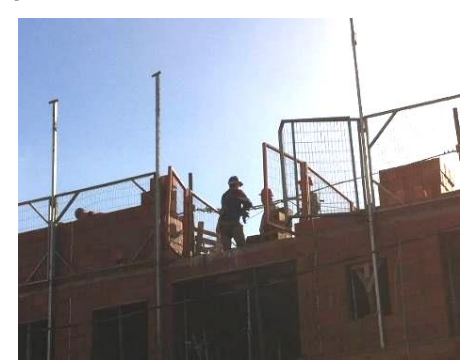

Foi observado que os SPP cuja instalação e remoção de montantes implica que parte do corpo dos trabalhadores esteja exposto para fora da periferia aumentam consideravelmente o risco de queda de pessoas (requisito 1). Um exemplo de SPP disponível no mercado foi selecionado para ilustrar as oportunidades de melhoria, conforme a Figura 16. O suporte metálico Surshield (2009) foi projetado para atender aos requisitos da norma OSHA 1926.502 (OCCUPATIONAL..., 1996). Composto de uma alça que abraça a estrutura de sustentação, esse suporte encaixa-se sem necessidade de furação e ajusta-se a planos horizontais e angulares tais como escadas. $\mathrm{O}$ mesmo é regulável em altura permitindo o uso em vigas de borda e lajes de diferentes espessuras. A instalação e remoção é rápida em função do acionamento do parafuso de tensão que fixa firmemente $\mathrm{o}$ suporte à estrutura de sustentação.

$\mathrm{Na}$ categoria eficiência foi salientado o não atendimento dos SPP-MA ao requisito 7 (reduzir o esforço físico nas atividades de montagem do SPP). Esse requisito merece importância não só pelas consequências que pode trazer para o trabalhador, tais como doenças e lesões graves, como pela dependência de outros dois requisitos: mecanismos de conexão entre componentes fáceis e rápidos; e boa produtividade nas tarefas de montagem e desmontagem (requisitos 4 e 11). A principal causa de não atendimento ao requisito 7 deve-se principalmente à fixação de peça por peça mediante pregos. Uma das oportunidades de melhoria identificadas refere-se à solução adotada 
no sistema Security Plast (2008). Este SPP atende aos requisitos normativos da UNE-EN 13374 (ASOCIACIÓN..., 2004) e OSHA (OCCUPATIONAL..., 1996) e é composto de montantes metálicos e placas fabricadas em material termoplástico com pequenas aberturas que se acoplam aos montantes através de travas de pressão incorporadas a eles (Figura 17). Tais mecanismos funcionam como dispositivos a prova de erros, uma vez que não admitem defeitos nas conexões entre componentes.

Com relação à flexibilidade o requisito 1 (o SPP prevê meios de acesso de pessoas e materiais a partir da periferia) foi o menos atendido, mesmo sendo considerado muito relevante, por ser exigido pela NR 18 (BRASIL, 2014b). Na análise em uso observou-se que em muitos casos os trabalhadores removem módulos do SPP para permitir o ingresso de materiais a partir da periferia, comprometendo a estabilidade de todo o sistema. Entre as oportunidades de melhorias foram selecionados dois exemplos:

(a) o sistema Grainger (2009), ilustrado na Figura 29, consiste num sistema de portas do tipo cancela e montantes extensíveis que se adaptam à parte interna do pavimento e se acoplam facilmente a qualquer tipo de SPP; e

(b) o sistema Schmidt (1998), constituído em aço, possui módulos que funcionam como portões - giram 90 graus a partir de um único ponto localizado no piso de trabalho sem precisar remover o modulo de lugar (Figura 30).

Figura 15 - Média total de atendimento por categoria

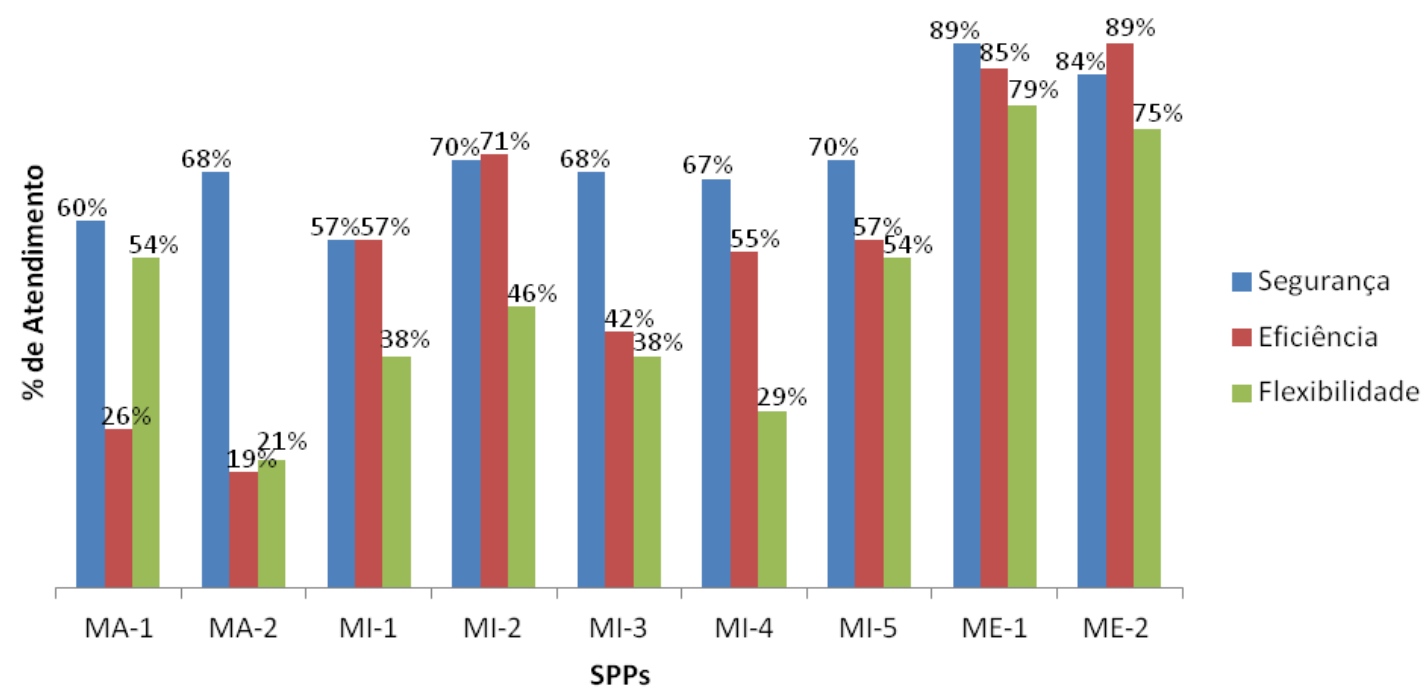

Figura 16 - Suporte metálico que pode facilitar a instalação e remoção do SPP
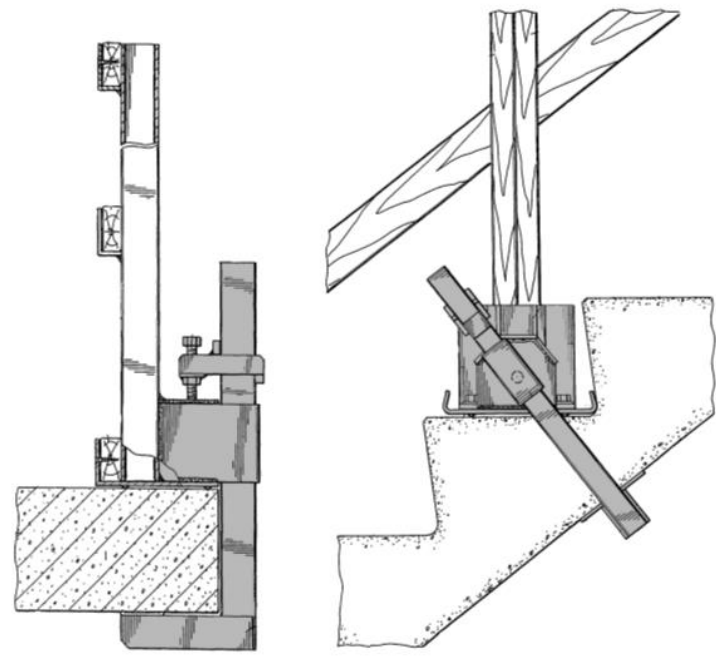

Fonte: adaptado de SurShield (2009). 
Figura 17 - (a) Aberturas das placas para travamento; (b) montante com travas incorporadas; e (c) vistas lateral e frontal do SPP instalado

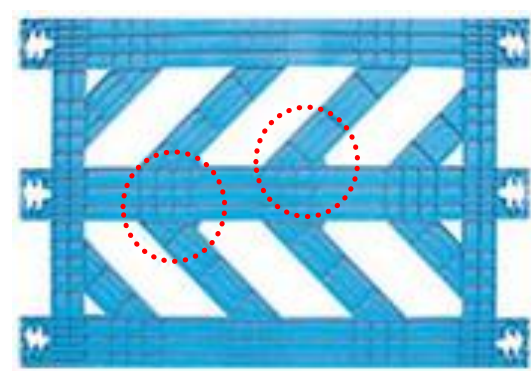

(a)

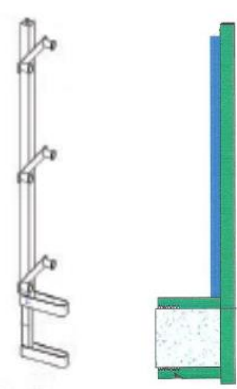

(b)

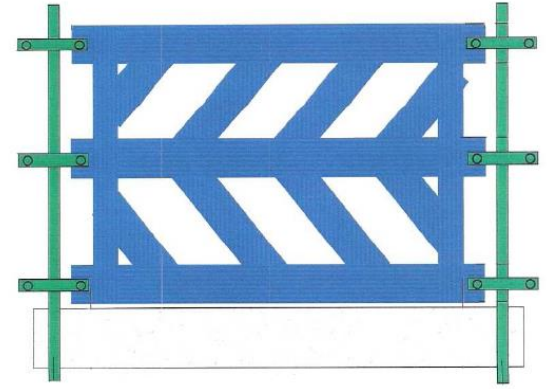

(c)

Fonte: adaptado de Security Plast (2008).

Figura 18 - Sistema de porta do tipo cancela

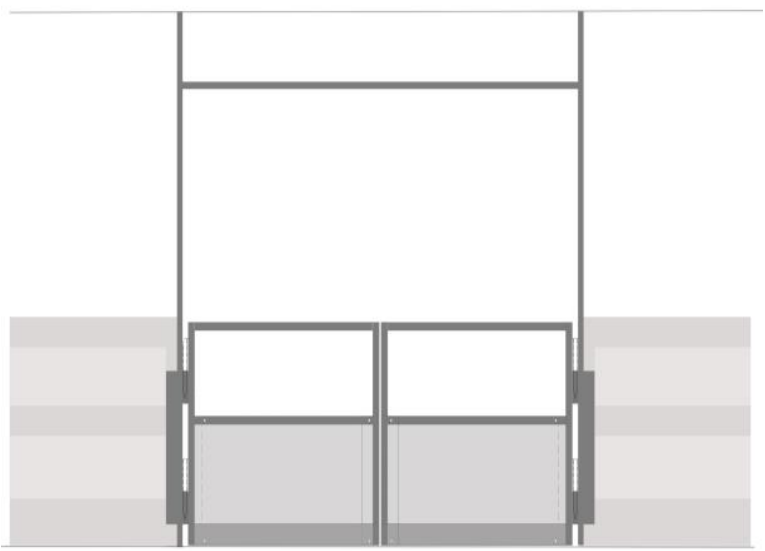

Fonte: adaptado de Grainger (2009).

Figura 19 - (a) SPP metálico fechado; (b) portão em posição semiaberta; e (c) portão em posição aberta

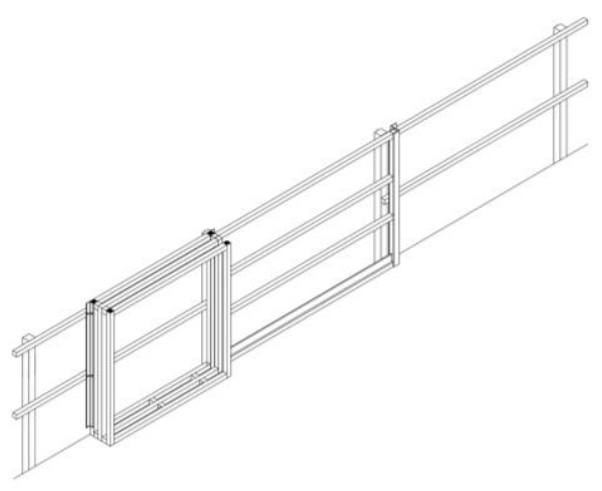

(a)

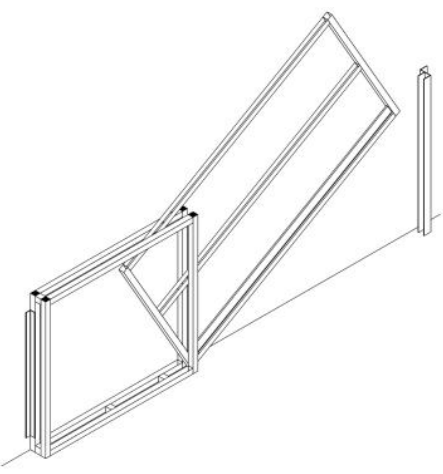

(b)

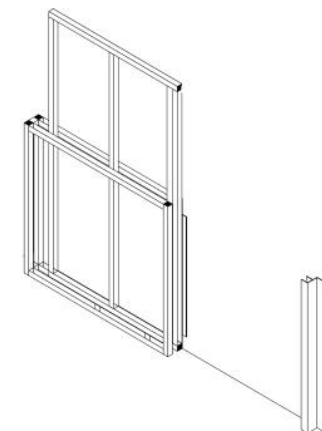

(c)

Fonte: adaptado de Schmidt (1998).

\section{Conclusões}

As principais contribuições deste estudo foram as seguintes:

(a) identificação e organização de requisitos; (b) identificação de requisitos não citados em normas, a partir da compreensão das necessidades dos usuários; $\mathrm{e}$

(c) categorização dos requisitos segundo a natureza de cada um.

Outra contribuição deste trabalho refere-se à identificação das principais vantagens e 
desvantagens dos SPP em madeira, mistos e metálicos, considerando um limitado número de tecnologias utilizadas na Região Metropolitana de Porto Alegre. Por um lado, as principais vantagens dos SPP em madeira e mistos são:

(a) baixo custo de aquisição em comparação com os SPP metálicos; e

(b) adaptação a diferentes configurações geométricas do ponto de vista da maleabilidade do sistema, permitindo cortar e ajustar os comprimentos de acordo com o cenário de uso.

Uma das vantagens dos SPP mistos sobre os SPP em madeira é a reutilização dos montantes metálicos, seja dentro da obra, seja em obras futuras. Por outro lado, as principais desvantagens dos SPP em madeira e mistos são:

(a) maior quantidade e variedade de componentes avulsos (10 unidades) em comparação com os SPP metálicos (3 componentes);

(b) na fixação dos componentes, a necessidade de pregar manualmente peça por peça sem seguir um critério definido (quantidade e espaçamento dos pregos) faz com que, ao longo do tempo, se perca a rigidez das conexões, favorecendo a remoção acidental dos componentes;

(c) baixo reaproveitamento da madeira;

(d) alto custo ao longo do ciclo de vida, já que os componentes em madeira precisam de manutenções periódicas e posteriormente são descartados; e

(e) grande volume de perdas e resíduos em função de cortes e erros de execução gerados a partir da montagem e desmontagem deles em comparação com os SPP metálicos.

Já as principais vantagens dos SPP metálicos são:

(a) materiais mais resistentes e duráveis em comparação com os SPP e madeira e misto;

(b) mecanismos de conexão rígidos e seguros entre os componentes mediante encaixes e travamentos integrados ao sistema;

(c) alto reaproveitamento;

(d) baixo custo ao longo do ciclo de vida;

(e) menos perdas e resíduos; e

(f) fácil de manipular por ser um sistema compacto com dispositivos incorporados.

Já o principal ponto fraco do SPP metálico referese ao projeto do rodapé. Alguns desses sistemas não possuem rodapé ou este é rejeitado pelos trabalhadores pelo fato de ser concebido como um elemento solto da tela de proteção, o que implica mais tempo e esforço no momento da instalação.
Dentro das limitações desta pesquisa, cabe ressaltar que não foi possível implementar as oportunidades de melhoria identificadas devido a limitações de prazo e recursos. Nesse sentido, foram identificadas algumas oportunidades para estudos futuros:

(a) testar as oportunidades de melhoria identificadas em possíveis soluções tecnológicas, contribuindo para incentivar o setor da construção a desenvolver inovações; e

(b) refinar e atualizar o conjunto de requisitos e critérios propostos, partindo da premissa de que o esforço de identificação de requisitos é um processo que evolui com o tempo e que depende das tecnologias disponíveis.

\section{Referências}

\author{
ASSOCIAÇÃO BRASILEIRA DE NORMAS \\ TÉCNICAS. NBR 15575-1: edificações \\ habitacionais: desempenho: parte 1: requisitos \\ gerais. Rio de Janeiro, 2013.
}

\section{ASOCIACIÓN ESPAÑOLA DE}

NORMALIZACIÓN Y CERTIFICACIÓN. UNE-

EN 13374: sistemas provisionales de protección de borde: especificaciones del producto, métodos de ensayo. Madrid, 2004.

BRASIL. Ministério do Trabalho e Emprego. NR 18: condições e meio ambiente de trabalho na indústria da construção. Disponível em: <http://portal.mte.gov.br/legislacao/normaregulamentadora-n-18-1.htm>. Acesso em: 11 abr. 2014 b.

BRASIL. Ministério do Trabalho e Emprego. NR 35: trabalho em altura. Disponível em: <http://portal.mte.gov.br/data/files.pdf > . Acesso em: 15 set. $2014 \mathrm{a}$.

BRASIL. Ministério do Trabalho e Emprego. NR 17: ERGONOMIA. Disponível em: <http://portal.mte.gov.br/data/files/FF8080812BE9 14E6012BEFBAD7064803/nr_17.pdf>. Acesso em: 12 out. $2014 \mathrm{c}$.

\section{BRASIL. Resultados da Fiscalização em} Segurança e Saúde no Trabalho: Brasil, 1996 a 2012. 2013. Disponível em:

<http://portal.mte.gov.br/seg_sau/resultados-dafiscalizacao-em-seguranca-e-saude-no-trabalhobrasil-1996-a-2009.htm>. Acesso em: 08 jul. 2014.

BROWN, L. A.; FRANK, J. S. Postural Compensations to the Potential Consequences of Instability: kinematics. Gait \& Posture, v. 6, n. 2, p. 89-97, oct. 1997. 
CAMBRAIA, F. B.; FORMOSO, C. T. Análise de Avanços e Retrocessos no Atendimento às Especificações da NR 18 nos Últimos Dez Anos. In: SIMPÓSIO BRASILEIRO DE GESTÃO E ECONOMIA DA CONSTRUÇÃO, Belém, 2011. Anais... Belém: ANTAC, 2011.

CAMERON, I.; GILLAN, G.; DUFF, A. R. Issues in the Selection of Fall Prevention and Arrest Equipment. Engineering, Construction and Architectural Management, v. 14, n. 4, p. 363374, 2007.

\section{CANADIAN CENTRE FOR OCCUPATIONAL} HEALTH AND SAFETY. CCOHS: Safety Code for the Construction Industry S-2.1, r.6: installation of guard-rails. 1981. Disponível em: <http://www2.publicationsduquebec.gouv.qc.ca/dy namicSearch/telecharge.php?type $=3 \&$ file $=/ S \_2 \_1 /$ S2_1R4_A.HTM>. Acesso em: 12 jul. 2014.

CHEUNG, E. Rapid Demountable Platform (RDP): a device for preventing fall from height accidents. Journal of Accident Analysis and Prevention, v. 48, n. 1, p. 235-245, 2012.

COSTELlA, M. F.; JUNGES, F. C.; PILZ, S. E. Avaliação do Cumprimento da NR 18 em Função do Porte de Obra Residencial e Proposta de Lista de Verificação da NR-18. Ambiente Construído, Porto Alegre, v. 14, n. 3, p. 87-102, jul./set. 2014.

FUNDACENTRO. Recomendações Técnicas de Procedimentos 01: medidas de proteção contra quedas de altura. Fundacentro, 2003. Disponível em: <http://www.fundacentro.gov.br dominios/CTN/anexos/Publicação/rtp01.pdf > Acesso em: 07 abr. 2013.

GAMBATESE, J. A.; BEHM, M.; HINZE, J. W. Viability of Designing for Construction Worker Safety. Journal of Construction Engineering and Management, v. 131, n. 9, p. 1029-1036, 2005.

GARCÍA, M. D. L. N. G. Consideraciones Respecto a los Sistemas Provisionales de Proteccíon de Borde. Universidad politécnica de Madrid, 2010.

GRAINGER. Safety Gate. 2009. Disponível em: <http://www.grainger.com/product/PS-DOORSPallet-Safety-Gate-

static.grainger.com/rp/s/is/image/Grainger/32.html >. Acesso em: 11 nov. 2014.

HOLlOMAN, J. H. United States Patent and Trademark Office. 1994. Disponível em: <http://www.uspto.gov/patentsUS5314167>. Acesso em: 15 jul. 2014.

HSIAO, H.; SIMEONOV, P. Preventing Falls From Roofs: a critical review. Ergonomics, v. 44, n. 5, p. 537-561, 2001.
JOHNSON, H. M.; SINGH, A.; YOUNG, R. Fall Protection Analysis For Workers on Residential Roofs. Journal of Construction Engineering and Management, v. 124, n. 5, p. 418-28, 1998.

KODAK, E. Ergonomic Design for People at Work. New York: John Wiley \& Sons. 1986. v. 2.

LAN, A.; DAIGLE, R. Development and Validation of a Method For Evaluating Temporary Wooden Guardrails Built and Installed on Construction Sites. Safety Science, v. 47, p. 215 226, 2009.

MALLMANN, B. S. Avaliação do atendimento aos requisitos da NR 18 em canteiros de obra. 2008. Trabalho de Conclusão de Curso (Engenharia Civil) - Escola de Engenharia, Universidade Federal do Rio Grande do Sul, Porto Alegre, 2008.

MARTINS, M. S. Diretrizes para elaboração de medidas de prevenção contra quedas de altura em edificações. São Carlos: Universidade Federal de São Carlos, 2004.

MCLAUGHLIN, J.; MCCOY, J. United States Patent and Trademark Office. 1976. Disponível em: <http://www.uspto.gov/patentsUS3995833>. Acesso em: 16 jul. 2014.

METRO FORM SYSTEM. Produtos: sistema de proteção Metro Form. 2009. Disponível em: <http://www.metroform.com.br/produto4.1.html>. Acesso em: 02 abr. 2014.

OCCUPATIONAL SAFETY AND HEALTH ADMINISTRATION. United States Department of Labour. 1926. 502: fall protection systems criteria and practices. 1996. Disponível em: <http://www.osha.gov/pls/oshaweb/owadisp.show _document?p_table=STANDARDS\&p_id=1 0758>. Acesso em: 13 ago. 2013.

ORMAN. Orman: sistemas de prevenção e proteção. 2012. Disponível em:

<http://www.grupoorman.com.br/page.aspx>.

Acesso em: 08 set. 2014.

OSTROW, P. United States Patent and

Trademark Office. 2001. Disponível em: <http://www.uspto.gov/patentsUS6220577>. Acesso em: 01 maio 2014.

RODGERS, S. Ergonomic Design For People at Work. New York: John Wiley \& Sons, 1986. v. 2.

SAURIN, T. A.; LANTELME, E.; FORMOSO, C. T. Contribuições para aperfeiçoamento da NR18: condições e meio ambiente de trabalho na indústria da construção. Porto Alegre:

Universidade Federal do Rio Grande do Sul, 2000. Relatório de Pesquisa. 
SCANMETAL. Trabalho e vida: proteção modulada de periferia de obras civis. 2011. Disponível em:

<http://www.trabalhoevida.com.br/download/scan manual.pdf>. Acesso em: 13 mar. 2013.

SCHMIDT. Pivot Gate. 1998. Disponível em: <http://www.schmidtstructural.com/products/hand rail-gates/pivot-gate.html>. Acesso em:19 mar. 2015.

SECURITY PLAST. Nuestro sistema: sistema de protección y seguridad para la obra. 2008.

Disponível em:

$<$ http://www.securityplast.com/es/nuestrosistema.html>. Acesso em: 3 abr. 2014.

SULOWSKI, A. C. Collective Fall Protection for Construction Workers. Informes de la

Construcción, v. 66, n. 533, 2014.

\section{SURSHIELD. The surshield guardrail clamp} system. 2009. Disponível em:

<http://www.safetyboot.com/surshield.html>. Acesso em: 11 nov. 2014.

THOMKE, S. The Role of Flexibility in the Development of New Products: an empirical study. Research Policy, v. 26, n. 1, p. 105-119, 1997.

TOOLE, T.; CARPENTER, G. Prevention Through Design: an important aspect of social sustainability. Integrating Sustainability Practices in the Construction Industry, p. 187195, 2012.

UPTON, D. M. Flexibility as Process Mobility: the management of plant capabilities for quick response manufacturing. Journal of Operations Management, v. 12, n. 3-4, p. 205-224, 1995.

Guillermina Andrea Peñaloza

Núcleo Orientado Para a Inovação da Edificação | Universidade Federal do Rio Grande do Sul | Av. Osvaldo Aranha, 99, $3^{\circ}$ andar, Bom Fim | Porto Alegre - RS - Brasil | CEP 90035-190 | Tel.: (51) 3308-3518 | E-mail: arq.guillerminapenaloza@gmail.com

\section{Carlos Torres Formoso}

Núcleo Orientado Para a Inovação da Edificação | Universidade Federal do Rio Grande do Sul | E-mail: formoso@ufrgs.br

\section{Tarcisio Abreu Saurin}

Programa de Pós Graduação em Engenharia de Produção | Universidade Federal do Rio Grande do Sul | Avenida Osvaldo Aranha, $99,5^{\circ}$ andar, Bom Fim | Porto Alegre - RS - Brasil | CEP 90035-190 | Tel.: (51) 3308-4299 | E-mail: saurin@ufrgs.br

\section{Revista Ambiente Construído}

Associação Nacional de Tecnologia do Ambiente Construído

Av. Osvaldo Aranha, 99 - $3^{\circ}$ andar, Centro

Porto Alegre - RS - Brasil

CEP $90035-190$

Telefone: +55 (51) 3308-4084

Fax: +55 (51) 3308-4054

www.seer.ufrgs.br/ambienteconstruido

E-mail: ambienteconstruido@ufrgs.br 